\title{
Misperceptions, heterogeneous expectations and macroeconomic dynamics*
}

\author{
Richard Harrison \\ Bank of England
}

\author{
Tim Taylor \\ Bank of England
}

\begin{abstract}
We investigate the extent to which misperceptions about the economy can become self reinforcing and thereby contribute to time-varying macroeconomic dynamics. To do so, we build a New Keynesian model with long-horizon expectations and dynamic predictor selection. Because agents solve multiperiod optimisation problems (households maximise expected lifetime utility and firms maximise the discounted flow of future profits), their current decisions are influenced by expectations of the infinite future and cannot in general be characterised by the Euler equations that typically represent the rational expectations equilibrium of these models. We assume that agents have access to a set of alternative predictors that can be used to form expectations. Agents choose among these predictors based on noisy measures of their recent performance. This dynamic predictor selection generates endogenous fluctuations in the proportions of agents using each predictor, contributing to macroeconomic dynamics.

We explore the behaviour of our model when agents have access to two simple predictors, one of which is consistent with a mistaken belief that macroeconomic variables are more persistent. We show that the presence of a 'persistent predictor' can lead to changes in beliefs which are self reinforcing, giving rise to endogenous fluctutions in the time series properties of the economy. Moreover, we show that such fluctuations arise even if we replace the 'persistent predictor' with learning under constant gain.
\end{abstract}

*This paper is preliminary and incomplete - please do not quote without the authors' permission. The views expressed in this paper are those of the authors and not necessarily those of the Bank of England. We would like to thank Charlie Bean, Cars Hommes and Peter Sinclair for useful discussions on earlier versions of this paper. All errors are ours. 


\section{Introduction}

The notion that expectations may be a source of economic fluctuations has a long history, dating back at least to Pigou (1929) and Keynes (1936). But the dominant paradigm in macroeconomics invokes rational expectations, which removes the possibility that endogenous changes in expectations formation may be an important source of economic dynamics. ${ }^{1}$ And we observe sharp changes in the time series properties of macroeconomic data, that are difficult to account for in standard rational expectations models. Within the rational expectations paradigm the focus has therefore been to investigate structural change or changes in policy to explain these properties, with less attention on the role of expectations.

Of course, academics have long debated the extent to which rational expectations can be considered reasonable a priori. Lucas (1986) argues that: ${ }^{2}$

the question whether people are in general "rational" or "adaptive" does not seem to me worth arguing over. Which of these answers is most useful will depend on the situations in which we are trying to predict behavior and on the experiences the people in question have had with such situations.

Monetary policymakers recognise the importance of this question too. Bernanke (2007) has recently asked: "What is the right conceptual framework for thinking about inflation expectations in the current context?" ${ }^{3}$ He argues that models of learning are useful deviations from the assumption of rational expectations, which seems inappropriate when there is structural change or uncertainty about policy objectives. Indeed, there is now a vast literature exploring models in which agents update the way they form expectations in the light of new data, capturing learning about the economy. ${ }^{4}$

The presence of non-rational expectations creates the potential for dynamic feedback between macroeconomic outcomes and expectations, as discussed, for example, in the Bank of England's February 2008 Inflation Report: ${ }^{5}$

\footnotetext{
${ }^{1}$ There is of course an extensive literature that examines the behaviour of 'indeterminate' rational expectations models. A recent example, applied to monetary policy issues, is Lubik \& Schorfheide (2004). Models of rational behaviour in which rational behaviour gives rise to 'higher order beliefs' have also been examined (see for example, Morris \& Shin (2003)).

${ }^{2}$ Page S402.

${ }^{3}$ Of course, many policymakers have voiced concerns about the possible sensitivity of the economy to alternative assumptions about the way firms and households form expectations (see, for example, King (2005)).

${ }^{4}$ A reference is Evans \& Honkapohja (2001). Evans \& Honkapohja (2008) provide a review recent literature review, with a focus on monetary policy applications. Sargent (2007) relates the lessons from learning models to a variety of historical episodes.

${ }^{5}$ Page 45.
} 
If households' and businesses' medium-term inflation expectations are heavily influenced by their recent experience, then repeated above-target outturns may cause them to place weight on the assumption that inflation will be persistently above [the inflation target of] $2 \%$ If those expectations were built into higher wages and prices, that would raise medium-term inflationary pressures.

In this paper we explore the dynamic feedback between outcomes and expectations in a benchmark New Keynesian model with long-horizon expectations and dynamic predictor selection. We solve the decision rules of households and firms conditional on their expectations for future events that are outside of their control. In this way the role played by expectations in the model is left explicit, so that spending and price-setting decisions depend on so-called 'longhorizon expectations' as articulated by Preston (2005). ${ }^{6}$ Specifically, households' consumption decisions depend on the discounted sum of expected future income and real interest rates and firms' prices depend on the discounted sum of their expected wage costs, productivity and inflation. A popular alternative approach is to use the behavioural equations of the model under rational expectations - which delivers Euler equations describing spending and inflation - and to replace the (rational) expectations terms with alternative expectations (see, for example, Evans \& Honkapohja (2001)). Both approaches can be defended as descriptions of (distinct) forms of boundedly rational behaviour. We prefer the description implied by the long-horizon expectations approach and employ them in our model. ${ }^{7}$

The feedback between outcomes and expectations is generated by dynamic predictor selection: the notion that agents choose between a small set of forecasting rules (or 'predictors') based on noisy observations of past performance. This approach has several advantages. First, it can bring about time variation in the persistence and variance of macroeconomic variables, as shown by Brazier et al. (2007). Second, it is consistent with experimental evidence about the way expectations are formed, and the way use of these rules varies over time (see, for example, Anufriev \& Hommes (2006)). And third, it allows different expectational rules to coexist: and such heterogeneity appears to be a feature of the survey data on expectations. We introduce predictor choice into our long horizon expectations model using the techniques developed by Brock \& Hommes (1997), Brock \& de Fontnouvelle (2000) and Branch \& Evans (2006), who in turn take as inspiration the discrete decision, multinomial logit models set out in Manski \& McFadden (1981).

We explore the interaction between the beliefs of firms and households and the properties of our model economy. We show that fluctuations in the expectations formation process -

\footnotetext{
${ }^{6}$ Models that incorporated this type of approach date back at least to Townsend (1983) and Sargent (1991).

${ }^{7}$ Harrison \& Taylor (2008) present evidence that the behaviour of the economy differs under the two alternatives may be significantly different, particularly when expectations are far from rational.
} 
the dynamic predictor selection which occurs endogenously in response to shocks - can bring about changes in the properties of the model that act (at least temporarily) to reinforce the initial change in beliefs. Misperceptions can for a time be self-reinforcing; and this mechanism is a candidate explanation for time-variation in the moments of data. Our approach is to investigate the behaviour of our model when agents have access to a predictor that (wrongly) anticipates that inflation shocks will be long-lasting (motivated in part by the quote from the Bank of England Inflation Report above). We show that misperceptions can indeed be temporarily self-reinforcing, leading to marked time-variation in the time series properties of the data. Moreover, this result survives even when agents' misperceptions are generated by a constant-gain learning algorithm.

Our paper is related to several (large) strands of the literature, as noted above. Our work is perhaps most closely related to that of Branch \& McGough (2006b), who introduce heterogeneous expectations in the familiar setting of a New Keynesian model. In subsequent work, Branch \& McGough (2006a) endogenise the proportion of agents using each predictor and examine the properties of a set of monetary policy rules. Our main innovations are that we examine predictor choice in the context of a model with long-horizon expectations and we allow one of the predictors to be updated over time via constant gain learning. While Milani (2007) estimates a model in which learning rules with different gain parameters are dynamically selected, he does not use a model with long-horizon expectations. Moreover, while learning models generally make the important step away from rational expectations by allowing agent's subjective expectations to deviate from those implied by the model, they typically assume homogeneity of expectations across agents. Incorporating dynamic predictor selection allows us both to separate subjective and model-consistent expectations and to introduce heterogeneity of expectations. Our model allows for both heterogeneity of individual agents (eg across different households) and between types of agents (eg firms and households may have access to different sets of predictors).

Section 2 sets out the model, which incorporates standard New Keynesian assumptions. We also describe the assumptions about expectations formation and the parameterisation of the model. Section 3 presents the results of our application, demonstrating that the presence of misperceptions about the persistence of macroeconomic data can be self-reinforcing. Section 4 concludes.

\section{The model}

Here we set out a baseline New Keynesian model and present the solution under alternative assumptions about expectations. A more detailed derivation is presented in Appendix A. So 
here we focus on the maximisation problems of the agents in the model and the associated log-linearised decision rules. We begin with the familiar rational expectations benchmark in Section 2.1 and in Section 2.2 we turn to the model under non-rational expectations. Since many of the equations carry over from the rational expectations version, we focus discussion on the decision rules of households and firms.

\subsection{The rational expectations benchmark}

In this section we describe the economic environment faced by agents in our model and characterise optimal behaviour and equilibrium under the assumption that expectations are rational.

\subsubsection{Households}

There is a continuum of households of unit mass, indexed by $i \in(0,1)$. We assume that household $i$ solves:

$$
\max E_{t-1} \sum_{s=t}^{\infty} \beta^{s-t}\left[\frac{c_{i, s}^{1-\sigma}-1}{1-\sigma}-\chi \frac{h_{i, s}^{1+\gamma}}{1+\gamma}\right]
$$

where $c$ is consumption and $h$ is hours worked and the parameters $\sigma$ and $\gamma$ are both strictly positive. ${ }^{8}$ We use $E_{t}$ to denote the mathematical expectations operator conditional on the information available to the household at date $t$. We impose the assumption that when making decisions about consumption at date $t$ and beyond, the household has access to data up to and including date $t-1$. This timing assumption is comparable with the informational assumptions that apply to agents that use non-rational predictors in the analysis of Section 2.2 .

More specifically, we assume that at the beginning of the period, the household forms a consumption plan before splitting its activities between a 'shopper' and a 'worker'. The shopper enters the goods market and purchases the consumption decided upon in the plan. The worker enters the labour market and supplies labour according the the intratemporal optimality condition relating consumption and labour supply, given the market wage. ${ }^{9}$

This type of approach has been used in a variety of rational expectations models under imperfect information, including (for example) Lucas (1980) and Rotemberg \& Woodford

\footnotetext{
${ }^{8}$ This rules out the case of linear disutility of work in utility $(\gamma=0)$. Given our informational assumptions (to be discussed), this case is problematic because households are unable to forecast their total labour income when their labour supply is demand determined.

${ }^{9}$ This timing assumption is necessary to ensure that the labour supply responds to meet demand. Given our assumptions about price setting behaviour - explained in Section 2.1.2 - if the household sets either the nominal wage or the amount of labour supplied based solely on date $t-1$ information, then the real wage is unable to move to the level required to clear the labour market.
} 
(1999). The latter is particularly interesting as it presents a sticky price New Keynesian model with rational expectations, under the assumption that consumption and pricing decisions are made on the basis of information sets that include only lagged values of endogenous variables. While they do not formally model the labour market, Rotemberg and Woodford's approach is in fact very similar to ours. They assume that households are producers as well as consumers and include the disutility from producing output in the household utility function. Because prices are set in advance of the shocks hitting the economy in the current period, output is demand determined. This means that households will in general produce more or less than they expected at the start of the period. This corresponds to the notion that the 'worker' of the household supplies more or less labour than anticipated at the start of the period in our model.

The household's budget constraint is

$$
B_{i, s}-R_{s-1} B_{i, s-1}-W_{s} h_{i, s}-D_{s}+P_{s} c_{i, s}=0
$$

where $B$ is the household's holdings of nominal (one period) bonds, $W$ is the nominal wage, $R$ measures the nominal interest rate paid on bonds, $D$ is a collection of transfers (from government and firms) and $P$ is the nominal price level.

Maximisation of utility gives rise to an Euler equation in consumption which can be written in log-linearised form as:

$$
\hat{c}_{t}=E_{t-1} \hat{c}_{t+1}-\sigma^{-1} E_{t-1}\left(\hat{R}_{t}-\hat{\Pi}_{t+1}\right)
$$

where we use the notation $\hat{x}_{t} \equiv \ln \left(x_{t} / x\right)$ for each variable $x_{t}$ to denote its log-deviation from its steady-state value, $x$. Our worker-shopper assumption means that the labour supply relationship is given by: ${ }^{10}$

$$
\hat{h}_{t}=\gamma^{-1} \hat{w}_{t}-\sigma \gamma^{-1} \hat{c}_{t}
$$

\subsubsection{Firms}

We assume that there are two types of firms - retailers and producers - and we consider each of them in turn.

Retailers are perfectly competitive and operate a production technology that combines the inputs of producers using a Dixit-Stiglitz technology:

$$
y_{t}=z_{t}\left[\int_{0}^{1} x_{j, t}^{1-\mu} d j\right]^{\frac{1}{1-\mu}}
$$

\footnotetext{
${ }^{10}$ The equation in the text differs from the planned labour supply at the start of the period (given by $\hat{h}_{t}^{p}=\gamma^{-1} E_{t-1} \hat{w}_{t}-\sigma \gamma^{-1} \hat{c}_{t}$ ) because the real wage adjusts to clear the labour market.
} 
where $x_{j}$ is the quantity of output purchased from producer $j, z$ is a productivity shock and $\mu>0$. We assume that the log-linearised behaviour of the shock $z$ is

$$
\hat{z}_{t}=\rho_{z} \hat{z}_{t-1}+u_{t}^{z}
$$

where $u^{z}$ is an iid shock and $\left|\rho_{z}\right|<1$.

Retailers sell their output to consumers and the government at nominal price $P$. Denoting the price of output purchased from producer $j$ as $P_{j}$, the cost-minimising price index for output is

$$
P_{t}=z_{t}^{-1}\left[\int_{0}^{1} P_{j, t}^{\frac{\mu-1}{\mu}} d j\right]^{\frac{\mu}{\mu-1}}
$$

and the associated demand curve for the output of producer $j$ is:

$$
x_{j, t}=z_{t}^{\frac{1-\mu}{\mu}}\left[\frac{P_{j, t}}{P_{t}}\right]^{-\frac{1}{\mu}} y_{t}
$$

The set of producers $j \in(0,1)$ produce differentiated products that form a Dixit-Stiglitz bundle consumed by households and the government. They produce using a constant returns in the single input (labour):

$$
x_{j, t}=a_{t} h_{j, t}
$$

where $a_{t}$ is a stochastic aggregate productivity term (common to all producers) and we assume that log-linearised productivity follows a simple $\operatorname{AR}(1)$ process:

$$
\hat{a}_{t}=\rho_{a} \hat{a}_{t-1}+u_{t}^{a}
$$

where $u^{a}$ is an iid shock and $\left|\rho_{a}\right|<1$.

Aggregating the production function across producers, combined with the production function of retailers, and log-linearising gives: ${ }^{11}$

$$
\hat{y}_{t}-\hat{z}_{t}=\hat{a}_{t}+\hat{h}_{t}
$$

The real profit of producer $j$ is:

$$
\Delta_{j t}=\frac{P_{j t}}{P_{t}} x_{j t}-w_{t} h_{j, t}=\left(\frac{P_{j t}}{P_{t}}-\frac{w_{t}}{a_{t}}\right) z_{t}^{\frac{1-\mu}{\mu}}\left(\frac{P_{j, t}}{P_{t}}\right)^{-\frac{1}{\mu}} y_{t}
$$

Under a Calvo pricing scheme, the objective function for a producer that is able to reset prices is thus:

$$
\max E_{t-1} \sum_{s=t}^{\infty} \Lambda_{s}(\beta \alpha)^{s-t}\left(\frac{P_{j t}}{P_{s}}-\frac{w_{s}}{a_{s}}\right)\left(\frac{P_{j, t}}{P_{s}}\right)^{-\frac{1}{\mu}} z_{s}^{\frac{1-\mu}{\mu}} y_{s}
$$

\footnotetext{
${ }^{11}$ The Dixit-Stiglitz aggregator for output is not equivalent to the simple sum of production functions across firms: there is a wedge between the two measures. This linearisation makes use of the fact that the distortion is second order so can be ignored when considering a linear approximation to the model. See Christiano et al. (2005) for a discussion.
} 
where $\Lambda$ represents the stochastic discount factor of a representative household and $0 \leq \alpha<1$ is the probability that the producer is not allowed to reset its price each period. As in the treatment of households, we assume that the producer's expectations are conditional on the information available up to the end of period $t-1$.

The log-linearised first order condition for newly set prices can be combined with the log-linearised expression for the retailer's price index to give:

$$
\begin{aligned}
\hat{\Pi}_{t}= & (1-\alpha)(1-\beta \alpha) E_{t-1}\left[\hat{w}_{t}-\hat{a}_{t}\right]+(1-\alpha) E_{t-1} \tilde{\Pi}_{t} \\
& +\alpha \beta E_{t-1} \hat{\Pi}_{t+1}-\rho_{z}\left(1-\alpha \beta \rho_{z}\right) z_{t-1}-u_{t}^{z}
\end{aligned}
$$

which is a version of the New Keynesian Phillips curve. ${ }^{12}$ In this expression, we have substituted out for the expectations of the future shock $z_{t+1}$ using the agents' knowledge of the process driving it and the fact that their information set is based on date $t-1$ information.

\subsubsection{Government and market clearing}

The government budget constraint is:

$$
B_{t}^{g}=R_{t-1} B_{t-1}^{g}+G_{t}-P_{t} \tau_{t}
$$

where $B^{g}$ is nominal government debt (one period bonds), $R$ is the nominal interest rate, $G(=P \times g)$ is nominal spending and $P \times \tau$ is nominal tax revenue. ${ }^{13}$ In real terms:

$$
b_{t}^{g}=\frac{R_{t-1}}{\Pi_{t}} b_{t-1}^{g}+g_{t}-\tau_{t}
$$

and we assume that the government issues no debt:

$$
B_{t}^{g}=b_{t}^{g}=0
$$

for all periods $t$. This means that the government runs a balanced budget each quarter and government spending is financed by (lump sum) tax revenue. The log-linearised expression for government spending is:

$$
\hat{g}_{t}=\rho_{g} \ln \hat{g}_{t-1}+u_{t}^{g}
$$

\footnotetext{
${ }^{12}$ Under the conventional assumption that expectations are based on information up to and including date $t$ we can exploit the fact that $E_{t} \hat{\Pi}_{t}=\hat{\Pi}_{t}$ and equation 6 becomes the standard New Keynesian Phillips curve:

$$
\hat{\Pi}_{t}=\frac{(1-\alpha)(1-\beta \alpha)}{\alpha}\left[\hat{w}_{t}-\hat{a}_{t}\right]+\beta E_{t} \hat{\Pi}_{t+1}+\left(\alpha \beta \rho_{z}-1\right) \hat{z}_{t}
$$

${ }^{13}$ We consider our model as the 'cashless limit' (Woodford (2003)) of an economy in which households demand fiat money, the issuance of which generates seignoreige for the government. We do so for analytical convenience since the inclusion of money would create an additional choice variable and associated decision rule for households.
} 
where $0 \leq \rho_{g} \leq 1$ and $u_{t}^{g}$ is iid.

Monetary policy is conducted using a Taylor rule with interest rate smoothing and an iid shock, which has the log-linearised representation:

$$
\hat{R}_{t}=\left(1-\phi_{r}\right)\left(\phi_{\pi} \hat{\Pi}_{t-1}+\phi_{y} \hat{y}_{t-1}\right)+\phi_{r} \hat{R}_{t-1}+u_{t}^{R}
$$

Market clearing dictates that all output is consumed by households or government:

$$
\hat{y}_{t}=\left(1-\psi_{g}\right) \hat{c}_{t}+\psi_{g} \hat{g}_{t}
$$

where $\psi_{g}$ is a parameter denoting the steady-state share of government expenditure in output.

\subsection{The model under non-rational expectations}

In this section we consider a variant of the model in which households and firms hold nonrational expectations. We will assume that households and firms employ relatively simple forecasting rules or 'predictors' to form their expectations. So in what follows, we will use the term 'predictors' as a shorthand for non-rational expectations.

The key point in this setup is that different agents may use different predictors and therefore make different decisions. This means that we need to pay attention to the heterogeneity across agents and then aggregate appropriately. Here we focus on how the decision rules of households and firms are affected by the use of non-rational expectations. We assume throughout that households (and firms) make their current decisions on the basis of their currently held expectations, without factoring in the possibility that those expectations will evolve as new information arrives. This is the 'anticipated utility' assumption that is extensively used in the literature on least squares learning. ${ }^{14}$ The anticipated utility approach makes it easier to write down the decision rules of individual households and firms, since they do not depend on the entire sequence of future forecasting rules that may be chosen and is thus very useful in delivering a tractable version of the model.

\subsubsection{Households}

As before we start with an individual household among the continuum of households of unit mass. Household $i \in(0,1)$ solves:

$$
\max \tilde{E}_{i, t-1} \sum_{s=t}^{\infty} \beta^{s-t}\left[\frac{c_{i, s}^{1-\sigma}-1}{1-\sigma}-\chi \frac{h_{i, s}^{1+\gamma}}{1+\gamma}\right]
$$

\footnotetext{
${ }^{14}$ The anticipated utility approach was introduced by Kreps (1998). Recent work by Cogley \& Sargent (2006) indicates that, in some circumstances, behaviour under anticipated utility can outperform that under rational expectations as an approximation to fully optimal behaviour.
} 
subject to

$$
b_{i, s}-\frac{R_{s-1}}{\Pi_{s}} b_{i, s-1}-w_{s} h_{i, s}-d_{s}+c_{i, s}=0
$$

where now we use the notation $\tilde{E}_{i}$ to denote the expectations of household $i$. The ${ }^{r}$ ' notation signals that the expectation is not rational and the $i$ subscript makes it clear that the expectation is specific to the individual household.

The Lagrangean for the problem is formed in the same way as in the rational expectations version and gives rise to the same first order conditions for $c_{i}, h_{i}$ and $b_{i}$, though with the expectation operator $\tilde{E}_{i, t-1}$ in place of the rational expectations operator $E_{t-1}$. The appendix demonstrates that the household's consumption is given by:

$$
\begin{aligned}
\hat{c}_{i, t}= & \frac{1-\beta}{1-\psi_{g}+\frac{\sigma(1-\mu)}{\gamma}} \tilde{E}_{i, t-1} \sum_{s=t}^{\infty} \beta^{s-t}\left(\begin{array}{c}
(1-\mu)\left(1+\gamma^{-1}\right) \hat{w}_{s} \\
+\beta^{-1} \tilde{b}_{i, t-1}+\left(\mu-\psi_{g}\right) \hat{d}_{s}
\end{array}\right) \\
& -\frac{\beta}{\sigma} \tilde{E}_{i, t-1} \sum_{s=t}^{\infty} \beta^{s-t}\left(\hat{R}_{s}-\hat{\Pi}_{s+1}\right)
\end{aligned}
$$

Equation 11 looks very much like a consumption function: current consumption depends on existing asset holdings plus the expected stream of future net income. So in this case - in constrast to the rational expectations version of the model - long-horizon expectations matter. ${ }^{15}$ The decision rules above therefore determine the household's choice variables as a function of the expected path of the variables outside of their control. In the following period, new shocks will have arrived, expectations will be updated and the household constructs a new consumption plan.

\subsubsection{Firms}

Since retailers do not form expectations, their behaviour is unaffected. And the environment faced by producers is essentially the same as that described in Section 2.1.2 though in this case the expectations of producer $j$ is denoted as the (non-rational) expectation $\bar{E}_{j, t}$. A producer $j$ given the chance to reset its price maximises:

$$
\max \bar{E}_{j, t-1} \sum_{s=t}^{\infty} \Lambda_{s}(\beta \alpha)^{s-t}\left(\frac{P_{j t}}{P_{s}}-\frac{w_{s}}{a_{s}}\right)\left(\frac{P_{j, t}}{P_{s}}\right)^{-\frac{1}{\mu}} z_{s}^{\frac{1-\mu}{\mu}} y_{s}
$$

\footnotetext{
${ }^{15}$ The assumption of non-rational expectations is not the only way in which long-horizon expectations may matter. For example, Rotemberg \& Woodford (1999) assume that the information delay differs across firms so that expectations based on information at dates $t-1$ and $t-2$ are relevant for pricing behaviour at date t. This assumption means that the conventional representation of the New Keynesian Phillips curve cannot be uncovered - so long-horizon expectations remain in their aggregate supply curve - see equation 22 on page 65 of Rotemberg \& Woodford (1999).
} 
which has a first order condition given by:

$$
\bar{E}_{j, t-1} \sum_{s=t}^{\infty} \Lambda_{s}(\beta \alpha)^{s-t}\left(\frac{\mu-1}{\mu} \frac{p_{j, t}}{\Pi_{t, s}}+\frac{1}{\mu} \frac{w_{s}}{a_{s}}\right)\left(\frac{p_{j, t}}{\Pi_{t, s}}\right)^{-\frac{1}{\mu}} z_{s}^{\frac{1-\mu}{\mu}} y_{s}=0
$$

where we define the price set by producer $j$ relative to the previous period's aggregate price level as:

$$
p_{j, t} \equiv \frac{P_{j, t}}{P_{t-1}}
$$

and the relative inflation factor

$$
\Pi_{t, s} \equiv \frac{P_{s}}{P_{t-1}}=\Pi_{s} \times \Pi_{s-1} \times \ldots \times \Pi_{t} \text { for } s \geq t
$$

where we normalise by the aggregate price level from the previous period because this is contained in producers' information set. ${ }^{16}$

Appendix A shows that linearising around the steady state described in Section A.1.4 gives the following pricing equation:

$$
\hat{p}_{j, t}=(1-\beta \alpha) \bar{E}_{j, t-1} \sum_{s=t}^{\infty}(\beta \alpha)^{s-t}\left(\hat{w}_{s}-\hat{a}_{s}\right)+\bar{E}_{j, t-1} \sum_{s=t}^{\infty}(\beta \alpha)^{s-t} \hat{\Pi}_{s}
$$

which makes it clear that if producers have different expectations about future costs and future inflation, then they will set different prices even when free to set them simultaneously.

\subsubsection{Aggregation}

To continue with the description of the model under heuristic expectations, we need to aggregate decisions of consumers and firms. We assume that there are a finite set of 'heuristics' or 'predictors' available to each group of agents. From this point on we will use the index $i(j)$ to denote the decisions of a household (firm) using predictor $i \in\{1, \ldots, I\}(j \in\{1, \ldots, J\})$.

This is appropriate if all agents that use the same predictors make the same decisions, which is the case if there is no dependence of current decisions on past decisions. Since households have access to financial assets that can be carried between periods, we need to carefully consider the aggregation of household decisions over time. Though the government issues a zero supply of one period nominal bonds each period, individual consumers can in principle trade with each other using these bonds. While the total net (private) supply of bonds across the population is zero (by market clearing) an individual household may carry forward a positive or negative bond position from the previous period, reflecting surprise

\footnotetext{
${ }^{16}$ Conventional treatments usually define the relative price of a firm $j$ in terms of the current aggregate price level: $p_{j, t} \equiv P_{j, t} / P_{t}$. There is no loss of generality in following our approach.
} 
income gains and losses. ${ }^{17}$ Fortunately, since we know that consumption plans are a linear function of previously accumulated financial assets, we can aggregate across households under reasonable assumptions. For example, aggregation is straightforward if we assume that the groups of households using each predictor (which pins down their view of human wealth) are either fixed or randomly drawn from the population as a whole. ${ }^{18}$

We assume that the mass of households (firms) using predictor $i(j)$ is given by $n_{i}\left(m_{j}\right)$ where

$$
\sum_{i=1}^{I} n_{i}=\sum_{j=1}^{J} m_{j}=1
$$

This means that the model equations can be written as follows. The average re-set price of producers is

$$
\begin{aligned}
& \hat{p}_{t}^{*}=\sum_{j=1}^{J} m_{j, t} \hat{p}_{j, t} \\
& =(1-\beta \alpha) \sum_{j=1}^{J} m_{j, t} \bar{E}_{j, t-1} \sum_{s=t}^{\infty}(\beta \alpha)^{s-t}\left(\hat{w}_{s}-\hat{a}_{s}\right)+\sum_{j=1}^{J} m_{j, t} \bar{E}_{j, t-1} \sum_{s=t}^{\infty}(\beta \alpha)^{s-t} \hat{\Pi}_{s}
\end{aligned}
$$

where, for each $j \in\{1, \ldots, J\}, m_{j}$ is the fraction of producers setting price $\hat{p}_{j}$. and inflation is given by:

$$
\hat{\Pi}_{t}=(1-\alpha) \hat{p}_{t}^{*}-\hat{z}_{t}
$$

The linearised resource constraint and monetary policy rule are the same as in the rational expectations model:

$$
\begin{gathered}
\hat{y}_{t}=\left(1-\psi_{g}\right) \hat{c}_{t}+\psi_{g} \hat{g}_{t} \\
\hat{R}_{t}=\left(1-\phi_{r}\right)\left(\phi_{\pi} \hat{\Pi}_{t-1}+\phi_{y} \hat{y}_{t-1}\right)+\phi_{r} \hat{R}_{t-1}+u_{t}^{R}
\end{gathered}
$$

The average level of consumption is:

$$
\begin{aligned}
\hat{c}_{t} & =\sum_{i=1}^{I} n_{i, t} \hat{c}_{i, t} \\
& =\frac{1-\beta}{1-\psi_{g}+\frac{\sigma(1-\mu)}{\gamma}} \sum_{i=1}^{I} n_{i, t} \tilde{E}_{i, t-1} \sum_{s=t}^{\infty} \beta^{s-t}\left[(1-\mu)\left(1+\gamma^{-1}\right) \hat{w}_{s}+\left(\mu-\psi_{g}\right) \hat{d}_{s}\right] \\
& -\frac{\beta}{\sigma} \sum_{i=1}^{I} n_{i, t} \tilde{E}_{i, t-1} \sum_{s=t}^{\infty} \beta^{s-t}\left(\hat{R}_{s}-\hat{\Pi}_{s+1}\right)
\end{aligned}
$$

\footnotetext{
${ }^{17}$ Consider a household that starts the period with no financial assets (bonds) and an overly pessimistic view of the future stream of future earnings. This household chooses to consume relatively little and receives a positive surprise when income exceeds expenditure during the period and hence ends the period with a higher level of financial assets than they had planned at the start of the period. Similarly, there will be other households that receive a negative surprise about net income and accumulate fewer bonds than they had anticipated.

${ }^{18}$ When the proportions are fixed over time, aggregate consumption depends linearly on the total bond holdings of households in the previous period (which sum to zero by market clearing). When the proportions change over time, but are composed of randomly selected households, the law of large numbers implies that the average financial wealth of households in each cohort is zero. Other assumptions can be made, though will typically require additional equations to keep track of the wealth distribution.
} 
where we use the fact that bond market clearing requires:

$$
\sum_{i=1}^{I} n_{i, s} \tilde{b}_{i, s}=0
$$

for all $s$.

\subsubsection{Specification of expectations}

So far we have considered households' and firms' decisions without taking a stand on how they form expectations. In this section we assume that they use backward-looking predictors, and specify a general form for those predictors. We also describe how households and firms choose which predictors to use: this allows us to complete the description of the model by providing an account of how the predictor proportions $n_{i},(i=1, \ldots, I)$ and $m_{j}(j=1, \ldots, J)$ are determined.

In the rest of this paper, and without loss of generality, we assume that $I=J=2$. For notation convenience for households we denote $n_{1}=n$ so that $n_{2}=1-n$. Similarly for firms we use the notation $m_{1}=m$ so that $m_{2}=1-m$. We assume that the fraction using each predictor evolves according to the observed forecast errors for that predictor. In particular the proportion $n$ at date $t$ is determined by: ${ }^{19}$

$$
n_{t}=\frac{1}{2} \tanh \left[-\frac{\theta_{h}^{\prime}}{4}\left(\Xi_{1, t}^{h}-\Xi_{2, t}^{h}\right)\right]+\frac{1}{2}
$$

where $\theta_{h}$ is a $4 \times 1$ vector of 'intensities of choice' and $\left(\Xi_{1, t}^{h}-\Xi_{2, t}^{h}\right)$ is the $4 \times 1$ vector of the differences of 'fitness measures' for the variables of interest for households ( $\hat{w}, \hat{d}, \hat{R}$ and $\hat{\Pi})$. The fitness measures are defined as geometric averages of past squared errors:

$$
\Xi_{i, t}^{h} \equiv \kappa_{h} S E_{i, t-1}+\left(1-\kappa_{h}\right) \Xi_{i, t-1}^{h}, i=1,2
$$

where $\kappa_{h}>0$ specifies the speed at which past mean squared errors are discounted (or equivalently, the effective window of past forecast errors that are used to evaluate the predictors).

We similarly assume that the choice of $m$ is governed by:

$$
m_{t}=\frac{1}{2} \tanh \left[-\frac{\theta_{f}^{\prime}}{3}\left(\Xi_{1, t}^{f}-\Xi_{2, t}^{f}\right)\right]+\frac{1}{2}
$$

where $\theta_{f}$ is a $3 \times 1$ vector of intensities of choice and $\left(\Xi_{1, t}^{f}-\Xi_{2, t}^{f}\right)$ is the $3 \times 1$ vector of the fitness measure for $\hat{w}, \hat{a}$ and $\hat{\Pi}$. This evolves according to

$$
\Xi_{j, t}^{f} \equiv \kappa_{f} S E_{j, t-1}+\left(1-\kappa_{f}\right) \Xi_{j, t-1}^{f}, j=1,2
$$

\footnotetext{
${ }^{19}$ This formulation comes from Branch (2004) and maps a $4 \times 1$ vector to the unit interval.
} 
For the greatest level of flexibility, we assume that households and firms use a VAR to form expectations of the variables that they care about. We define the vector of endogenous variables as $\xi_{t}=\left[\begin{array}{llllllllllll}\hat{c}_{t} & \hat{y}_{t} & \hat{\Pi}_{t} & \hat{p}_{t}^{*} & \hat{w}_{t} & \hat{R}_{t} & \hat{d}_{t} & \hat{a}_{t} & \hat{g}_{t} & \hat{z}_{t}\end{array}\right]^{\prime}$ and the vector of three (i.i.d.) exogenous

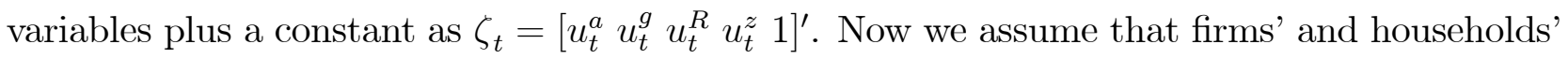
expectations of endogenous variables are generated by a general VAR forecasting model of the following form:

$$
\xi_{t}=F \xi_{t-1}+G \zeta_{t}
$$

This form permits a wide variety of forecasting models. For example, if we assume that the fourth column of $G$ is equal to a zero vector and specify $F$ so that the largest eigenvalue is less than 1 in magnitude, then expectations will ultimately converge to the steady state values of endogenous variables described in Section A.1.4. Setting both the $F$ and $G$ matrices to zero generates the 'steady state predictors' analysed in Brazier et al. (2007).

This approach means that, for firms, we have:

$$
\bar{E}_{j, t} \xi_{t+s}=F_{f, j}^{s}\left(F_{f, j} \xi_{t-1}+G_{f, j} \zeta_{t}\right) \text { for } j=1, \ldots, J
$$

and for households:

$$
\tilde{E}_{i, t} \xi_{t+s}=F_{h, i}^{s}\left(F_{h, i} \xi_{t-1}+G_{h, i} \zeta_{t}\right)
$$

The current period decisions for consumption and prices depend on discounted sums of expected future outturns. We can transform our VAR forecasting model to perform these summations. So for example, for some arbitrary $F, G$ and discount rate $\delta \in(0,1)$ we have:

$$
\begin{aligned}
\sum_{s=0}^{\infty} \delta^{s} \tilde{E}_{t-1} \xi_{t+s} & =\left(\sum_{s=0}^{\infty} \delta^{s} F^{s}\right)\left(F \xi_{t-1}+G \zeta_{t}\right) \\
& =(I-\delta F)^{-1}\left(F \xi_{t-1}+G \zeta_{t}\right)
\end{aligned}
$$

which is valid as long as the eigenvalues of $F$ are all less than $\beta^{-1}$ in absolute magnitude.

Two equations in the model contain terms with expectation operators: firms' price equation and households' consumption equation. Starting with firms, we have:

$$
\begin{aligned}
\hat{p}_{t}^{*} & =\sum_{j=1}^{2} m_{j, t} \hat{p}_{j, t} \\
& =\sum_{j=1}^{2} m_{j, t}\left((1-\beta \alpha) \bar{E}_{j, t-1} \sum_{s=t}^{\infty}(\beta \alpha)^{s-t}\left(\hat{w}_{s}-\hat{a}_{s}\right)+\bar{E}_{j, t-1} \sum_{s=t}^{\infty}(\beta \alpha)^{s-t} \hat{\Pi}_{s}\right) \\
& =\sum_{j=1}^{2} m_{j, t}\left((1-\beta \alpha) \bar{E}_{j, t-1} \sum_{s=t}^{\infty}(\beta \alpha)^{s-t} \hat{w}_{s}-(1-\beta \alpha) \bar{E}_{j, t-1} \sum_{s=t}^{\infty}(\beta \alpha)^{s-t} \hat{a}_{s}+\bar{E}_{j, t-1} \sum_{s=t}^{\infty}(\beta \alpha)^{s-t} \hat{\Pi}_{s}\right)
\end{aligned}
$$

Now we can use the VAR representation of expectations and perform the summations as above using the VAR coefficient matrices. We use selector matrices - denoted $S \cdot$ - to pick out 
the summation of the forecast for the variable of interest: thus $S^{x}$ is the matrix that selects the forecast error for the variable $x$. So the pricing equation can be written as:

$$
\hat{p}_{t}^{*}=\sum_{j=1}^{2} m_{j, t}\left[\begin{array}{c}
(1-\beta \alpha) S^{w}\left(I-\beta \alpha F_{f, j}\right)^{-1}\left(F_{f, j} x_{t-1}+G_{f, j} z_{t}\right) \\
-(1-\beta \alpha) S^{a}\left(I-\beta \alpha F_{f, j}\right)^{-1}\left(F_{f, j} x_{t-1}+G_{f, j} z_{t}\right) \\
+S^{\pi}\left(I-\beta \alpha F_{f, j}\right)^{-1}\left(F_{f, j} x_{t-1}+G_{f, j} z_{t}\right)
\end{array}\right]
$$

Collecting terms, and defining $V_{f, j} \equiv\left(I-\beta \alpha F_{f, j}\right)^{-1}$ gives:

$$
\hat{p}_{t}^{*}=\sum_{j=1}^{2} m_{j, t}\left[\left((1-\beta \alpha)\left(S^{w}-S^{a}\right)+S^{\pi}\right) V_{f, j}\left(F_{f, j} x_{t-1}+G_{f, j} z_{t}\right)\right]
$$

Analogous arguments can be applied to the consumption equation of households giving:

$$
\begin{aligned}
\hat{c}_{t} & =\sum_{i=1}^{2} n_{i, t} \hat{c}_{i, t} \\
& =\sum_{i=1}^{2} n_{i, t}\left[\left(k_{1} S^{w}+k_{2} S^{d}-\frac{\beta}{\sigma} S^{R}+\frac{\beta}{\sigma} S^{\pi} F_{h, i}\right) V_{h, i}\left(F_{h, i} x_{t-1}+G_{h, i} z_{t}\right)\right]
\end{aligned}
$$

where, $V_{h, i} \equiv\left(I-\beta F_{h, i}\right)^{-1}$ and

$$
k_{1}=\frac{(1-\beta)(1+\gamma)}{\left(1-\psi_{g}\right) \frac{\gamma}{1-\mu}+\sigma} ; \quad k_{2}=\frac{(1-\beta)\left(\mu-\psi_{g}\right)}{\left(1-\psi_{g}\right)+(1-\mu) \frac{\sigma}{\gamma}}
$$

\subsection{Model parameters}

The parameters can be divided into two groups. First, the so-called 'deep' parameters of the model describe the preferences and constraints of households and firms and must be specified in order to solve the model under rational expectations. Second, the parameters that are

\begin{tabular}{|c|c|c|c|}
\hline$\alpha$ & 0.75 & $\beta$ & 0.99 \\
\hline$\gamma$ & 0.50 & $\sigma_{z}$ & 0.50 \\
\hline$\sigma$ & 2.26 & $\sigma_{g}$ & 2.14 \\
\hline$\frac{1}{\mu}$ & 10.0 & $\sigma_{r}$ & 0.97 \\
\hline$\psi_{g}$ & 0.22 & $\sigma_{a}$ & 1.79 \\
\hline$\phi_{\pi}$ & 1.50 & $\rho_{g}$ & 0.30 \\
\hline$\phi_{y}$ & 0.125 & $\rho_{z}$ & 0.10 \\
\hline$\phi_{r}$ & 0.25 & $\rho_{a}$ & 0.60 \\
\hline
\end{tabular}
specific to the non rational expectations version of the model. We consider each group in turn.

\subsection{1 'Deep' parameters}

The table below documents the choice of the key parameters of the model. 
The calibration of $\beta$ is standard in this type of model as is the choice of $\alpha$ (implying a duration of price contracts of one year). We calibrate $\sigma$ and $\psi_{g}$ representing the, the coefficient of relative risk aversion and the share of government spending in output from the estimates of Nelson \& Nikolov (2002) using UK data. We also set the variance of the productivity process $\left(\sigma_{a}^{2} /\left(1-\rho_{a}^{2}\right)\right)$ to be the same as their estimates, though we choose a lower persistence $\left(\rho_{a}\right)$. The reason for this choice is to allow the potential for the model to generate endogenous changes in persistence that do not depend on the forcing processes driving the model. Similarly we choose a low value for the autocorrelation of the government spending process $\left(\rho_{g}\right)$ and we set its variance equal to the variance of the productivity process. We assume that the cost push shocks have a relatively low persistence $\left(\rho_{z}\right)$ and variance $\left(\sigma_{z}^{2}\right)$ compared with the other shocks. This choice is designed to ensure that cost push shocks play a relatively minor role so that there is some scope for misperceptions about those shocks to generate somewhat different views about the behaviour of the economy. This is an important aspect of the application we present in Section 3.

The specification of the monetary policy rule implies long-run coefficients on inflation and output $\left(\phi_{\pi}\right.$ and $\left.\phi_{y}\right)$ in line with Taylor (1993) and a moderate degree of interest rate smoothing $\phi_{r}=0.25$. Again, we want to allow the predictor choice mechanisms to have some potential to materially affect the persistence and variability of the variables in the model. The variance of monetary policy shocks is consistent with the midpoint of a range of estimates of Taylortype rules on UK data. The Frisch elasticity of labour supply $\left(\gamma^{-1}\right)$ is somewhat larger than typical empirical estimates from DSGE models (see for example Smets \& Wouters (2003)). This assumption helps to keep the overall variability of the model in a plausible range and is important given the key role of the real wage in clearing the labour market. The elasticity of demand in product markets $\frac{1}{\mu}$ is set to imply a markup of $10 \%$ which is in line with estimates using UK data.

\subsection{2 'Expectations' parameters}

The expectations parameters are those that govern the predictor choice mechanism. The 'intensities of choice' determine the extent to which agents switch to better performing predictors. So, for households, the proportion of households choosing predictor 1 (of the two available) is given by equation (13) introduced in Section 2.2.4. The vector $\theta_{h}$ represents the intensities of choice for the household. If each element of $\theta_{h}$ tends to infinity, then all agents immediately switch to the best performing predictor (as measured by the average difference in mean squared error). Conversely, if each element of $\theta_{h}$ tends to zero, agents are indifferent between the two predictors, regardless of their relative performance so that $n=1-n=0.5$. 
The mapping described by this function can be motivated by appealing to a story in which agents observe the true relative predictor performance with noise. The extreme of infinitely large $\theta_{h}$ elements corresponds to the case in which the variance of noise is zero and the extreme of $\theta_{h}=0$ corresponds to a situation in which the variance of the noise is infinitely large. As described in Section 2.2.4, there is an analogous function that governs the choice of predictors by firms and the intensities of choice in this function $\left(\theta_{f}\right)$ are calibrated jointly with those for households.

Because the intensities of choice affect the choice of predictors by households and firms, the choice of these parameters is clearly important for the behaviour of the model. Our approach to calibrating them is based on the view that we want the elements of the $\theta_{h}$ and $\theta_{f}$ to compensate for the fact that some variables that agents forecast may be far more volatile than others. For example, the household must forecast dividend payments, which could be significantly more volatile than other variables that the household forecasts (for example inflation). Our strategy proceeds in two steps. First, we set the elements of $\theta \equiv\left\{\theta_{h}, \theta_{f}\right\}$ so that each element of an 'average fitness measure' vector is equalised

$$
\left[\begin{array}{c}
n \Xi_{1, t}^{h}+(1-n) \Xi_{2, t}^{h} \\
m \Xi_{1, t}^{f}+(1-m) \Xi_{2, t}^{f}
\end{array}\right]=\iota
$$

where $\iota$ is the unit vector. Appendix B describes the details of the algorithm, which uses an asymptotic representation of the model in which the predictor proportions $n$ and $m$ are determined according to the predictor choice equations. Because the first step is based on an asymptotic representation of the model (in which the fitness measure coincides with the mean squared error), it can only pin down the relative size of the elements in $\theta$. So the second step is to rescale the entire $\theta$ vector to ensure that there is sufficient predictor switching in dynamic simulations of the model. This procedure leads to the following settings for the intensities of choice:

\begin{tabular}{ccc}
\hline \hline & $\theta_{h}$ & $\theta_{f}$ \\
\hline$\Pi$ & 21.2 & 21.2 \\
$w$ & 2.0 & 2.0 \\
$R$ & 4.8 & - \\
$d$ & 0.01 & - \\
$a$ & - & 2.2 \\
\hline
\end{tabular}

The other parameters that are important for the dynamic behaviour of the model are those that control the extent to which agents discount past mean squared errors when computing the fitness measure. We set these parameters to $\kappa_{h}=0.03$ and $\kappa_{f}=0.06$, based on gain parameters estimated using survey measures of inflation expections. [To be completed]. 


\section{Self-reinforcing misperceptions}

In this section we explore the interaction between the beliefs of firms and households and the properties of our model economy. We show that fluctuations in the expectations formation process - the dynamic predictor selection which occurs endogenously in response to shocks - can bring about changes in the properties of the model that act (at least temporarily) to reinforce the initial change in beliefs. Misperceptions can for a time be self-reinforcing; and this mechanism is a candidate explanation for time-variation in the moments of data.

Our approach is to investigate the behaviour of our model when agents have access to a predictor that (wrongly) anticipates that inflation shocks will be long-lasting. We start by motivating our experiments, before detailing how we have implemented misperceptions, and reporting results. Finally, we contrast the results with the case in which agents have access to a constant-gain learning algorithm.

\subsection{Misperceptions about macroeconomic persistence}

The idea that changes in beliefs may become self reinforcing is one that is of obvious concern to policymakers. In particular, the risk that elevated inflation expectations can become embedded in the wage and price setting process is one that monetary policy makers seek to avert. This is illustrated by the quote from the Bank of England's February 2008 Inflation Report, cited in the Introduction:

If households' and businesses' medium-term inflation expectations are heavily influenced by their recent experience, then repeated above-target outturns may cause them to place weight on the assumption that inflation will be persistently above $2 \%$. If those expectations were built into higher wages and prices, that would raise medium-term inflationary pressures.

The quote recognises the potential for beliefs about the economy (expectations of persistently high inflation) to lead to changes in behaviour (higher wages and prices) that reinforce that belief (higher medium-term inflationary pressure).

We use this concern on the part of policymakers to motivate our analysis in this section. We explore the extent to which, if agents begin to use predictors that embed assumptions of greater macroeconomic persistence, these beliefs may become self-reinforcing. And we study whether this type of mechanism can materially affect the behaviour of our model economy, and generate time-variation in the moments of the data generated by the model. 


\subsection{Implementing misperceptions in our model}

To place some structure on the beliefs that agents in our model hold, we consider the following scenario. In line with our focus on non-rational expectations, we limit all agents in the model to forecast using $\mathrm{AR}(1)$ forecasting rules. A forecasting rule that serves as a natural benchmark in this environment is one that brings about a form of restricted perceptions equilibrium. $^{20}$ When all agents hold these beliefs, the data generating process of the model is such that, subject to their restricted perceptions, agents' beliefs are confirmed. With this in mind, we posit that households and firms are unsure about the degree of persistence in the variables on which their decisions depend. Specifically, agents choose between two alternative restricted perception forecasting rules: a benchmark rule consistent with the true processes for the shocks in the economy (the best-performing $\mathrm{AR}(1)$ forecasting rule, if all agents share these beliefs, which we call the restricted perceptions predictor or RPP); and an alternative rule consistent with the misperception that the cost-push shock is persistent $\left(\rho_{z}=0.9\right)$, when in fact it is not. We call the second predictor the 'misperceptions predictor' (MP).

The alternative beliefs are reported in Table 1, which lists the $\operatorname{AR}(1)$ coefficients that characterise our two forecasting rules. We run 500 simulations of 4000 periods each, using the model calibration detailed in Section 2.3, allowing agents to choose between the forecasting rules as described. We discard the first 2000 periods of data from each run and compute statistics on the remaining periods. We focus on the distribution of variance and persistence estimates computed on non-overlapping samples of length 40 periods, for inflation, interest rates and output. These we compare to the equivalent statistics derived from simulations in which agents share common beliefs: in one case rational expectations (RE), and in another the benchmark restricted perceptions predictor (RPP).

\begin{tabular}{ccc}
\hline \hline & $\mathrm{RPP}$ & $\mathrm{MP}$ \\
$z$ & 0.10 & 0.90 \\
$\Pi$ & 0.20 & 0.77 \\
$R$ & 0.28 & 0.61 \\
$c$ & 0.44 & 0.87 \\
$y$ & 0.31 & 0.65 \\
$d$ & 0.40 & 0.70 \\
$w$ & 0.16 & 0.82 \\
$a$ & 0.60 & 0.60 \\
$g$ & 0.30 & 0.30 \\
\hline
\end{tabular}

Table 1: AR(1) coefficients describing RPP and MP forecasting rules

\footnotetext{
${ }^{20}$ See, for example, Branch (2004).
} 


\subsection{Implications of misperceptions}

When agents can choose between the two forecasting rules, the model generates time-variation in the moments of the data.

Table 2 reports summary statistics for the distribution of variance estimates (the 5th, 50th and 95th percentiles). Figure 1 plots a kernel density estimate of the distribution of variance estimates for inflation. Similarly, Table 3 and Figure 2 charaterise the distribution of persistence estimates. The simple measure of persistence used is the first-order serial correlation coefficient (allowing for a constant term in the regression).

For inflation and interest rates, the median estimates of variance and persistence are markedly higher in the misperceptions case than when expectations are rational. Output is more variable but no more persistent. Moreover, the distributions are positively skewed, indicating the model's ability to generate periods of particularly volatile or persistent outcomes. This is a direct consequence of the non-linearity that the predictor switching mechanism entails.

\begin{tabular}{|c|c|c|c|c|c|c|c|c|c|c|c|c|}
\hline & \multicolumn{3}{|c|}{$\mathrm{RE}$} & \multicolumn{3}{|c|}{$\mathrm{RPP}$} & \multicolumn{3}{|c|}{$\begin{array}{l}\text { Switching: } \\
\text { RPP/MP }\end{array}$} & \multicolumn{3}{|c|}{$\begin{array}{c}\text { Switching: } \\
\text { RPP/learning }\end{array}$} \\
\hline & 5 & 50 & 95 & 5 & 50 & 95 & 5 & 50 & 95 & 5 & 50 & 95 \\
\hline$\Pi$ & 0.19 & 0.29 & 0.42 & 0.18 & 0.27 & 0.40 & 0.21 & 0.35 & 1.07 & 0.19 & 0.29 & 0.48 \\
\hline$r$ & 0.88 & 1.35 & 1.96 & 0.89 & 1.37 & 2.02 & 0.99 & 1.63 & 3.38 & 0.92 & 1.43 & 2.18 \\
\hline$y$ & 0.22 & 0.33 & 0.50 & 0.17 & 0.26 & 0.38 & 0.22 & 0.38 & 0.92 & 0.17 & 0.28 & 0.46 \\
\hline
\end{tabular}

Table 2: Summary statistics for variances

The top panel of Figure 3 shows an illustrative run of simulated data, comparing in the blue and green lines respectively the paths for inflation when all agents' beliefs coincide with the RPP, and when agents are allowed to switch between the RPP and the MP. At the start of the period the paths for inflation are little different under the alternative assumptions about beliefs. Consistent with this, the dashed green line in the second panel of the figure is close to 0 , indicating that almost all firms' beliefs are given by the RPP. After about 40 periods a succession of large negative draws of the productivity shock begins to push inflation up. At this time the behaviour of inflation is more accurately forecasted by the MP, which embodies the misperceived belief that the cost-push shock, and hence inflation, is highly persistent. Large forecast errors for the RPP cause households and firms to switch to the MP. With more persistent beliefs about the inflation process, lagged inflation gains higher weight in the price setting process, and actual inflation is more persistent also. In this sense, the shift towards the misperceived beliefs is self-reinforcing. 


\subsection{Misperceptions through constant gain learning}

Our experiments so far have allowed for agents' beliefs to be consistent with an arbitrary misperception. But there are plausible mechanisms through which such misperceptions may arise endogenously in response to realisations of data. One example that has received much attention in the literature is adaptive learning (see Honkapohja and Evans 2001). In this section we explore whether agents in our model choose to use a constant-gain learning process to inform their expectations, when they have a choice between learning and the RPP that we have described already. We find that at times they do, and that this has qualitatively similar but quantitatively smaller effects on the time series properties of the model economy compared to the arbitrary misperceptions case we described earlier.

We repeated exactly the same set of experiments as in the previous section, now allowing agents to switch between the RPP and a forecasting rule informed by a constant-gain learning process. The results are detailed in the fourth columns of Tables 2 and 3. Comparing them to the benchmark case where beliefs are common at the RPP, we note that there are small increases in the variability of 40 period estimates of persistence and volatility which are most noticeable in the upper tail of the distribution of inflation persistence estimates. This is clear from the red line in Figure 2.

For much of the time the learning rule generates belief that are similar to the RPP. This is intuitive: if the economy is behaving as if agents use the RPP, then the learning rule is close to the RPP, agents are indifferent between it and the RPP, and outturns are such as to validate both the RPP and the learning rule. Returning to the top panel of Figure 3, this is the situation at the start of the period shown. But the remainder of the simulation shows that large shocks can cause a divergence of the path taken by inflation when large shocks come along.

The third panel of Figure 3 shows the AR(1) coefficient for inflation estimated under the learning processes used by firms and households. As inflation rises, so does its estimated persistence. The performance of the learning and RPP predictors diverge, and firms and households switch to using the learning predictor (as illustrated in the second panel of the Figure). This tends to increase the persistence of inflation; and so on.

In general learning mitigates the fluctuations in inflation that occur in the case where the alternative to the RPP predictor is the (fixed) MP. However at times learning can result in beliefs that are closer to the MP, and the behaviour of the economy alters accordingly. So we cannot rule out that endogenously generated fluctuations in beliefs can be self-reinforcing, and generate time variation in economic dynamics. 


\begin{tabular}{|c|c|c|c|c|c|c|c|c|c|c|c|c|}
\hline & \multicolumn{3}{|c|}{$\mathrm{RE}$} & \multicolumn{3}{|c|}{$\mathrm{RPP}$} & \multicolumn{3}{|c|}{$\begin{array}{l}\text { Switching: } \\
\text { RPP/MP }\end{array}$} & \multicolumn{3}{|c|}{$\begin{array}{l}\text { Switching: } \\
\text { RPP/MP }\end{array}$} \\
\hline & 5 & 50 & 95 & 5 & 50 & 95 & 5 & 50 & 95 & 5 & 50 & 95 \\
\hline$\Pi$ & -0.23 & 0.03 & 0.30 & -0.09 & 0.18 & 0.42 & 0.01 & 0.40 & 0.78 & -0.08 & 0.23 & 0.56 \\
\hline$R$ & -0.05 & 0.21 & 0.44 & 0.00 & 0.27 & 0.49 & 0.07 & 0.38 & 0.69 & 0.02 & 0.29 & 0.53 \\
\hline$y$ & -0.01 & 0.27 & 0.50 & -0.01 & 0.25 & 0.48 & -0.05 & 0.23 & 0.48 & 0.00 & 0.26 & 0.49 \\
\hline
\end{tabular}

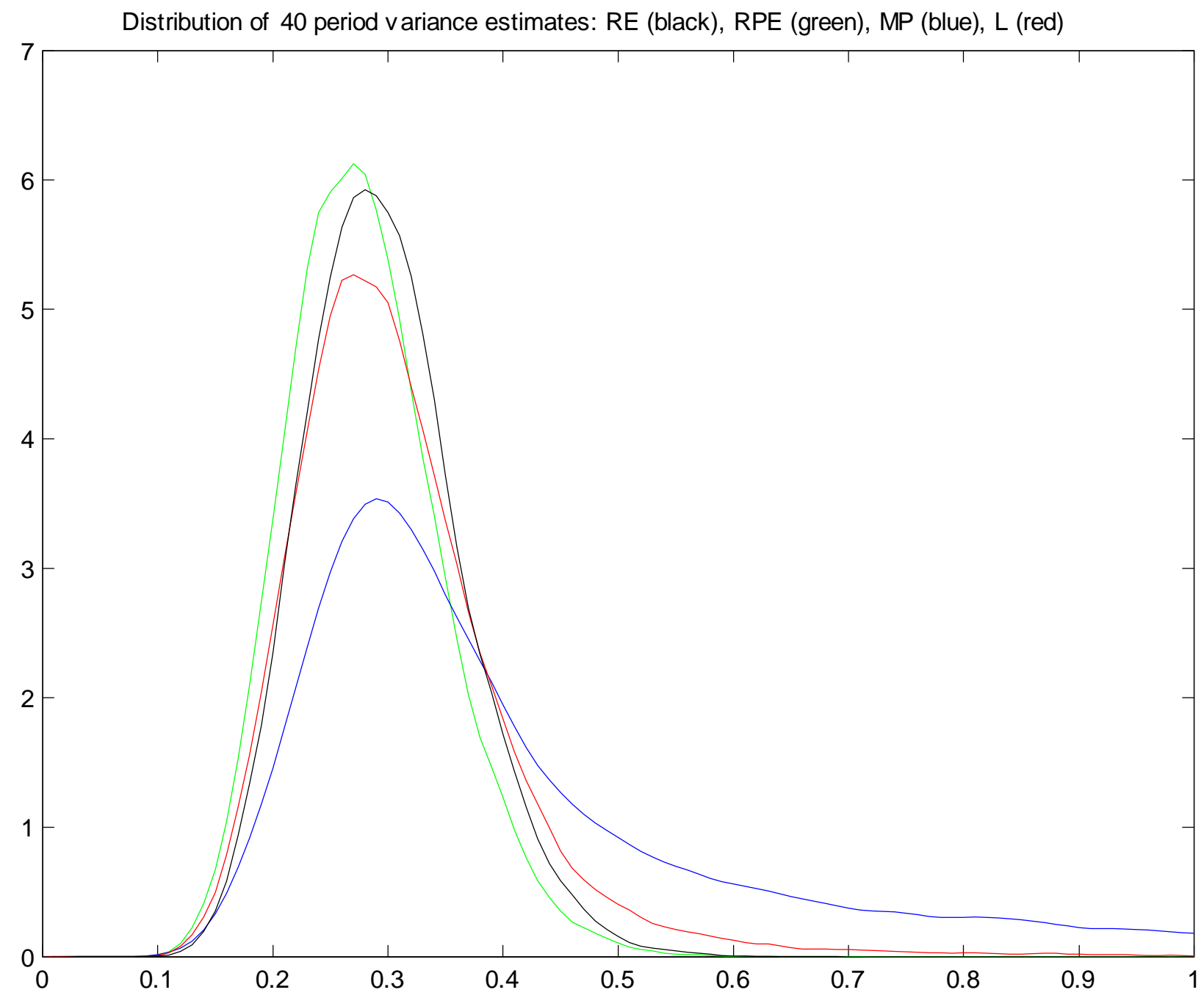

Figure 1: Distributions of inflation variances 


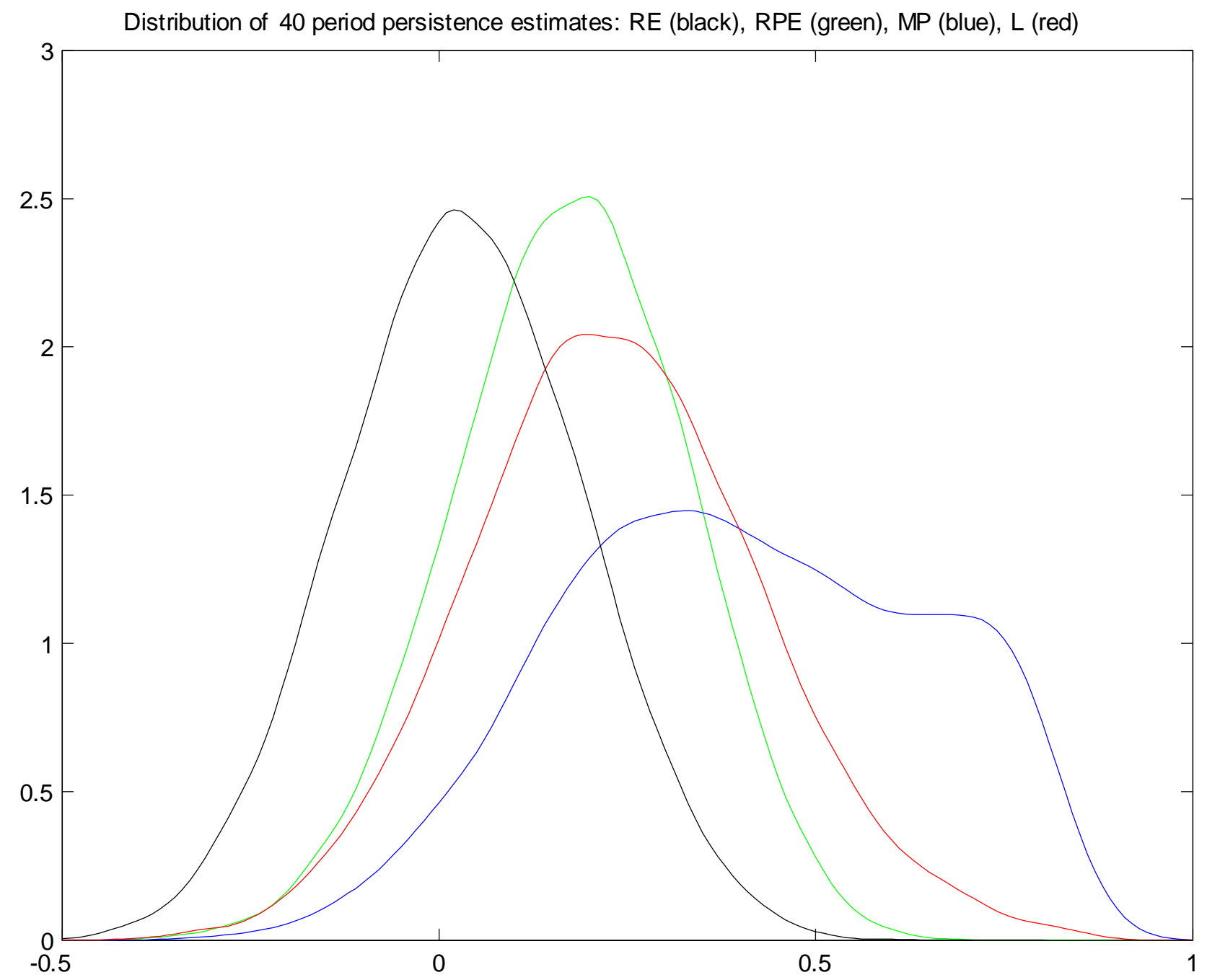

Figure 2: Distribution of inflation persistence measures

\section{Conclusions}

[To be completed] 


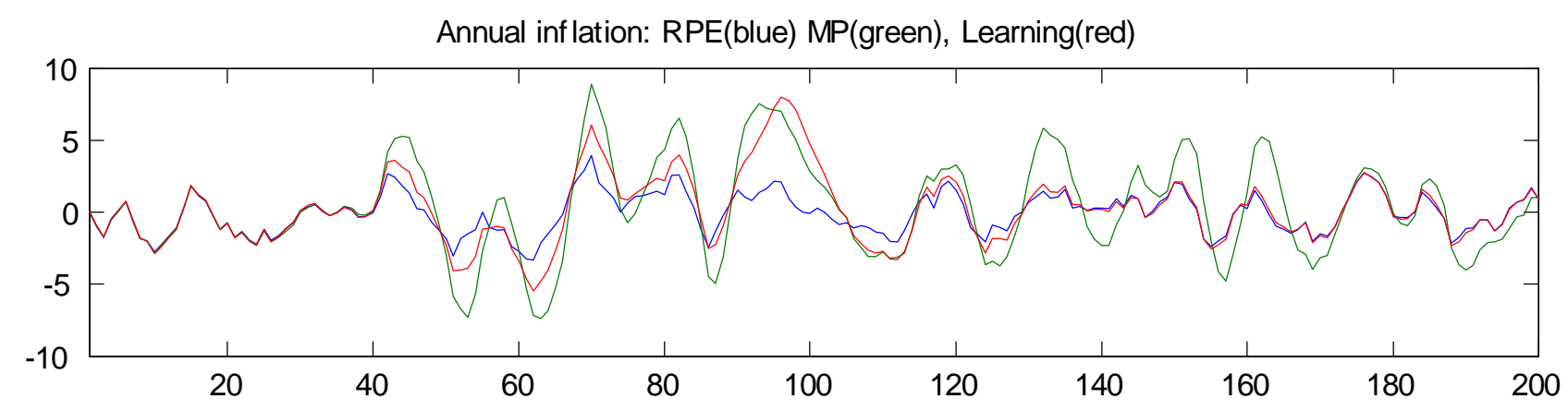

Predictor dist: MP(green), Learning(red); households(solid), firms(dash)

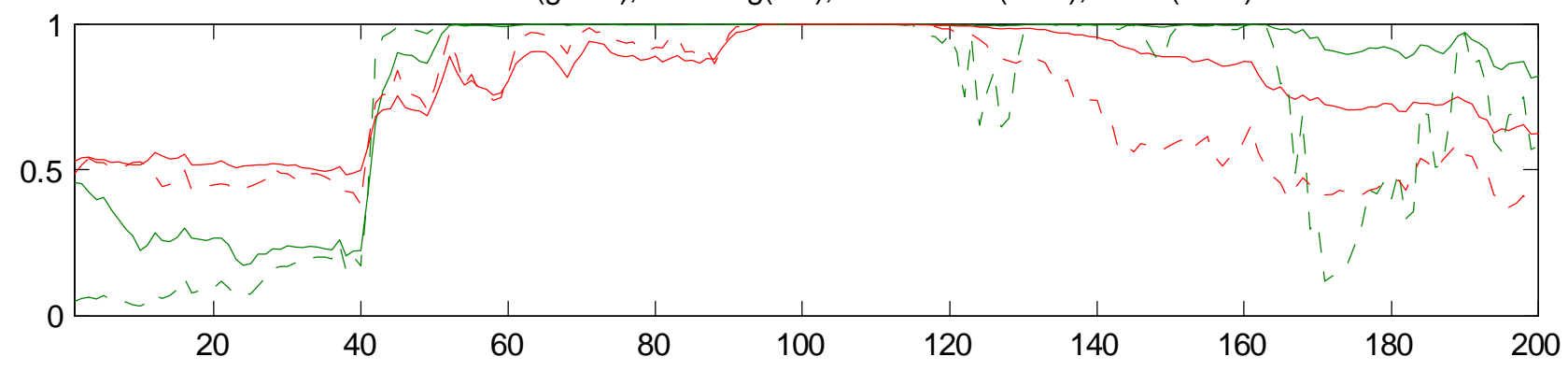

Arcoeff under learning: households(solid), firms(dash)

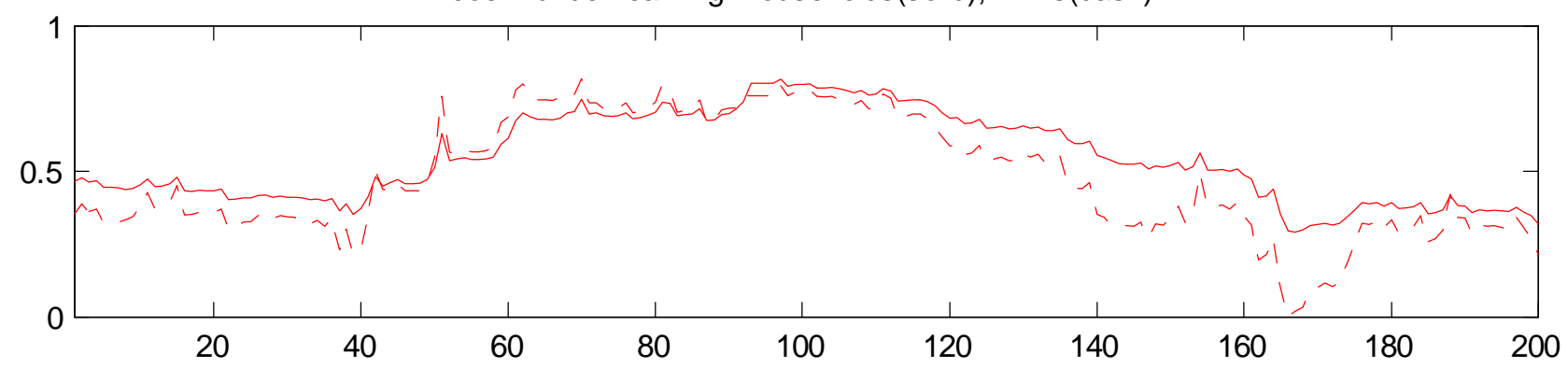

Figure 3: Inflation behaviour under alternative assumptions about beliefs: top panel is annual inflation; middle panel, fraction of agents using misperceptions/learning predictor; bottom panel, estimated inflation persistence in learning predictor

\section{References}

Anufriev, M., \& Hommes, C. H. 2006. Evolution of Market Heuristics. CeNDEF Working paper 07-06 University of Amsterdam.

Bernanke, B. 2007. Inflation Expectations and Inflation Forecasting. Speech delivered at the Monetary Economics Workshop of the National Bureau of Economic Research Summer Institute.

Branch, W. 2004. Restricted Perceptions Equilibria and Learning in Macroeconomics. In: 
Colander, D. (ed), Post Walrasian Macroeconomics: Beyond the Dynamic Stochastic General Equilibrium Model.

Branch, W., \& Evans, G. 2006. Intrinsic heterogeneity in expectations formation. Journal of Economic Theory, 127(1), 264-95.

Branch, W., \& McGough, B. 2006a. Dynamic predictor selection in a New Keynesian model with heterogeneous expectations. mimeo.

Branch, W., \& McGough, B. 2006b. A New Keynesian model with heterogeneous expectations. mimeo.

Brazier, A., Harrison, R., King, M., \& Yates, T. 2007. The danger of inflating expectations of macroeconomic stability: heuristic switching in an overlapping generations monetary model. In: Monetary policy: a journey from theory to practice. An ECB colloquium in honour of Otmar Issing. European Central Bank.

Brock, W., \& de Fontnouvelle, P. 2000. Expectational diversity in monetary economies. Journal of Economic Dynamics and Control, 24(6), 725-59.

Brock, W., \& Hommes, C. 1997. A rational route to randomness. Econometrica, 65, 1,059-95.

Christiano, L., Evans, G., \& Eichenbaum, M. 2005. Nominal rigidities and the dynamic effect of a shock to monetary policy. Journal of Political Economy, 113(1), 1-45.

Cogley, T., \& Sargent, T. 2006. Anticipated utility and rational expectations of Bayesian decision making. mimeo.

Evans, G., \& Honkapohja, S. 2001. Learning and expectations in macroeconomics. Princeton University Press.

Evans, G., \& Honkapohja, S. 2008. Expectations, learning and monetary policy: an overview of recent research. CDMA Working paper 08/02.

Harrison, R., \& Taylor, T. 2008. Non-rational expectations and the transmission mechanism. mimeo.

Keynes, J. M. 1936. The general theory of employment, interest and money. MacMillan, New York.

King, M. 2005. Monetary policy: practice ahead of theory, Mais lecture 2005. Bank of England Quarterly Bulletin, 226-236. 
Kreps, D. 1998. Anticipated utility and dynamic choice. In: Jacobs, D. P., Kalai, E., \& Kamien, M. (eds), Frontiers of research in economic theory. Cambridge University Press.

Lubik, T., \& Schorfheide, F. 2004. Testing for indeterminacy: an application to US monetary policy. American Economic Review, 94(1), 190-217.

Lucas, R. E. 1980. Equilibrium in a pure currency economy. In: Kareken, J., \& Wallance, N. (eds), Models of monetary economics. Federal Reserve Bank of Minneapolis.

Lucas, R. E. 1986. Adaptive behaviour and economic theory. Journal of Business, 59(2), S401-S426.

Manski, C., \& McFadden, D. 1981. Structural analysis of discrete data with econometric applications. MIT press, Cambridge.

Milani, F. 2007. Learning and Time-Varying Macroeconomic Volatility. mimeo, University of California.

Morris, S., \& Shin, H. 2003. Social value of public information. American Economic Review, 92(5), 1521-1534.

Nelson, E., \& Nikolov, K. 2002. Monetary policy and stagflation in the UK. Bank of England Working Paper.

Pigou, A. C. 1929. Industrial fluctuations, 2nd Ed. MacMillan, London.

Preston, B. 2005. Learning about monetary policy rules when long horizon expectations matter. International Journal of Central Banking, 1(2), 81-126.

Rotemberg, J., \& Woodford, M. 1999. Interest rate rules in an estimated sticky price model. In: Taylor, J. (ed), Monetary Policy Rules. NBER.

Sargent, T. 1991. Equilibrium with signal extraction from endogenous variables. Journal of Economic Dynamics and Control, 15(2), 245-73.

Sargent, T. 2007. Evolution and intelligent design. mimeo.

Smets, F., \& Wouters, R. 2003. An estimated DSGE model for the Euro Area. Journal of the European Economic Association, 1(5), 1123-1175.

Taylor, J. 1993. Discretion versus policy rules in practice. Carnegie-Rochester Conference Series on Public Policy, 39, 195-214. 
Townsend, R. 1983. Forecasting the forecasts of others. Journal of Political Economy, 91(4), 546-88. 


\section{A Derivation of the model}

\section{A.1 The rational expectations case}

\section{A.1.1 Households}

As noted in the main text, household $i$ solves:

$$
\max E_{t-1} \sum_{s=t}^{\infty} \beta^{s-t}\left[\frac{c_{i, s}^{1-\sigma}-1}{1-\sigma}-\chi \frac{h_{i, s}^{1+\gamma}}{1+\gamma}\right]
$$

subject to

$$
b_{i, s}-\frac{R_{s-1}}{\Pi_{s}} b_{i, s-1}-w_{s} h_{i, s}-d_{s}+c_{i, s}=0
$$

The Lagrangean for the problem is:

$$
\max E_{t-1} \sum_{s=t}^{\infty} \beta^{s-t}\left[\begin{array}{c}
(1-\sigma)^{-1}\left(c_{i, s}^{1-\sigma}-1\right)-\frac{\chi}{1+\gamma} h_{i, s}^{1+\gamma} \\
-\lambda_{i, s}\left(b_{i, s}-\frac{R_{s-1}}{\Pi_{s}} b_{i, s-1}-w_{s} h_{i, s}-d_{s}+c_{i, s}\right)
\end{array}\right]
$$

and the first order conditions for $c_{i}, h_{i}$ and $b_{i}$ are:

$$
\begin{gathered}
E_{t-1}\left[c_{i, s}^{-\sigma}-\lambda_{i, s}\right]=0 \\
E_{t-1}\left[-\chi h_{i, s}^{\gamma}+\lambda_{i, s} w_{s}\right]=0 \\
E_{t-1}\left[-\lambda_{i, s}+\frac{\beta R_{s}}{\Pi_{s+1}} \lambda_{i, s+1}\right]=0
\end{gathered}
$$

\section{A.1.2 Firms}

As noted in the text, the first order condition for a producer resetting its price at date $t$ is:

$$
E_{t-1} \sum_{s=t}^{\infty} \Lambda_{s}(\beta \alpha)^{s-t}\left(\frac{\mu-1}{\mu} \frac{1}{P_{s}}+\frac{1}{\mu} \frac{w_{s}}{P_{j, t} a_{s}}\right)\left(\frac{P_{j, t}}{P_{s}}\right)^{-\frac{1}{\mu}} z_{s}^{\frac{1-\mu}{\mu}} y_{s}=0
$$

or

$$
E_{t-1} \sum_{s=t}^{\infty} \Lambda_{s}(\beta \alpha)^{s-t}\left(\frac{\mu-1}{\mu} \frac{p_{j, t}}{\Pi_{t, s}}+\frac{1}{\mu} \frac{w_{s}}{a_{s}}\right)\left(\frac{p_{j, t}}{\Pi_{t, s}}\right)^{-\frac{1}{\mu}} z_{s}^{\frac{1-\mu}{\mu}} y_{s}=0
$$

if we define the price set by firm $j$ relative to the previous period's aggregate price level as:

$$
p_{j, t} \equiv \frac{P_{j, t}}{P_{t-1}}
$$

and the relative inflation factor

$$
\Pi_{t, s} \equiv \frac{P_{s}}{P_{t-1}}=\Pi_{s} \times \Pi_{s-1} \times \ldots \times \Pi_{t} \text { for } s \geq t
$$


where we normalise by the aggregate price level from the previous period because this is contained in firms' information set.

Since all firms are identical in terms of their information and production constraints, all firms that are able to change prices at date $t$ will choose the same price, which we denote as $p_{t}^{*}$. Thus

$$
E_{t-1} \sum_{s=t}^{\infty} \Lambda_{s}(\beta \alpha)^{s-t}\left(\frac{\mu-1}{\mu} \frac{p_{t}^{*}}{\Pi_{t, s}}+\frac{1}{\mu} \frac{w_{s}}{a_{s}}\right)\left(\frac{p_{t}^{*}}{\Pi_{t, s}}\right)^{-\frac{1}{\mu}} z_{s}^{\frac{1-\mu}{\mu}} y_{s}=0
$$

The reatiler's price is:

$$
\begin{aligned}
P_{t} & =z_{t}^{-1}\left[\int_{0}^{1} P_{j, t}^{\frac{\mu-1}{\mu}} d j\right]^{\frac{\mu}{\mu-1}} \\
& =z_{t}^{-1}\left[\sum_{k=0}^{\infty}(1-\alpha) \alpha^{k}\left(P_{t-k}^{*}\right)^{\frac{\mu-1}{\mu}}\right]^{\frac{\mu}{\mu-1}}
\end{aligned}
$$

where the equality follows from grouping the firms into cohorts according to the date at which they last reset their price and noting that the mass of firms that have not reset their price since date $t-k$ is $(1-\alpha) \alpha^{k}$. This means that the aggregate price level can be written as

$$
P_{t}=z_{t}^{-1}\left[\alpha P_{t-1}^{\frac{\mu-1}{\mu}}+(1-\alpha)\left(P_{t}^{*}\right)^{\frac{\mu-1}{\mu}}\right]^{\frac{\mu}{\mu-1}}
$$

so that

$$
1=\alpha\left(\frac{1}{z_{t} \Pi_{t}}\right)^{\frac{\mu-1}{\mu}}+(1-\alpha)\left(\frac{p_{t}^{*}}{z_{t} \Pi_{t}}\right)^{\frac{\mu-1}{\mu}}
$$

\section{A.1.3 Government and market clearing}

The government budget constraint is:

$$
B_{t}^{g}=R_{t-1} B_{t-1}^{g}+G_{t}-P_{t} \tau_{t}
$$

where $B^{g}$ is nominal government debt (one period bonds), $R$ is the nominal interest rate, $G$ is nominal spending and $P \times \tau$ is nominal tax revenue. ${ }^{21}$ In real terms:

$$
b_{t}^{g}=\frac{R_{t-1}}{\Pi_{t}} b_{t-1}^{g}+g_{t}-\tau_{t}
$$

and we assume that the government issues no debt:

$$
B_{t}^{g}=b_{t}^{g}=0
$$

\footnotetext{
${ }^{21}$ We consider our model as the 'cashless limit' (Woodford (2003)) of an economy in which households demand fiat money, the issuance of which generates seignoreige for the government. We do so for analytical convenience since the inclusion of money would create an additional choice variable and associated decision rule for households.
} 
for all periods $t$. This means that the government runs a balanced budget each quarter and government spending is financed by tax revenue. Government spending follows an exogenous process:

$$
\ln g_{t}=\rho_{g} \ln g_{t-1}+\left(1-\rho_{g}\right) \ln g+u_{t}^{g}
$$

where $0 \leq \rho_{g} \leq 1$ and $u_{t}^{g}$ is iid. We use $g$ to denote the steady state level of government spending.

Monetary policy is conducted using a Taylor rule with interest rate smoothing and an iid shock:

$$
\frac{R_{t}}{R}=\left[\left(\frac{\Pi_{t-1}}{\Pi}\right)^{\phi_{\pi}}\left(\frac{y_{t-1}}{y}\right)^{\phi_{y}}\right]^{1-\phi_{r}}\left(\frac{R_{t}}{R}\right)^{\phi_{r}} \exp \left[u_{t}^{R}\right]
$$

where again variables without subscripts are steady-state values.

Market clearing dictates that all output is consumed by households or government: ${ }^{22}$

$$
y_{t}=c_{t}+g_{t}
$$

A corollary of this market clearing condition is that the market for nominal one period bonds also clears. This requires that

$$
b_{t}^{a g g}=b_{t}+b_{t}^{g}=0
$$

where $b_{t}^{a g g}$ denotes the real-valued supply of all (private and publicly issued) nominal bonds. Given that government debt issuance is zero, we require that the net supply of private bonds is zero: $b_{t}=0$. Because all households are identical, this means that no consumer issues or holds debt in equilibrium. Another implication of this assumption is that all households choose the same level of consumption:

$$
c_{i, t}=c_{t}
$$

As noted in Section 2.1.1, the 'worker' of the household supplies labour according to the intratemporal labour supply condition based on the market real wage:

$$
\chi h_{i, t}^{\gamma}=c_{i, t}^{-\sigma} w_{t}
$$

Finally, the total transfers to consumers consist of dividends net of lump sum taxes:

$$
d_{t}=\Delta_{t}-\tau_{t}
$$

\footnotetext{
${ }^{22}$ This holds under the conventional assumption that households and government consume the same basket of goods, which they purchase at the same price.
} 
in equilibrium this is given by: ${ }^{23}$

$$
d_{t}=y_{t}-w_{t} h_{t}-g_{t}
$$

or

$$
d_{t}=c_{t}-w_{t} h_{t}
$$

\section{A.1.4 Steady state}

We now consider a steady state around which the model equations will be linearised. We assume that steady-state inflation (ie the inflation target) is $\Pi=1$ which means that the Euler equation gives

$$
R=\beta^{-1}
$$

Since steady-state productivities are $a=z=1$, this immediately this implies:

$$
y=h
$$

and from market clearing and the specification of steady state government spending, we have:

$$
y=c+g=c+\psi_{g} y
$$

so that:

$$
c=\left(1-\psi_{g}\right) y
$$

where $\psi_{g}$ is the (exogenous) steady state share of government procurement in output.

From the pricing equation in steady state, we see that:

$$
w=1-\mu
$$

Using the results above in the labour supply function implies

$$
\chi h^{\gamma+\sigma}=\left(1-\psi_{g}\right)^{-\sigma}(1-\mu)
$$

which means that if we choose the weight on disutility from work to be

$$
\chi=\left(1-\psi_{g}\right)^{-\sigma}(1-\mu)
$$

then the steady state solution satisfies

$$
y=h=1
$$

These observations allow us to express steady-state dividends as:

$$
d=c-w h=\left(1-\psi_{g}-(1-\mu)\right) y=\mu-\psi_{g}
$$

\footnotetext{
${ }^{23}$ This equality follows from the fact that firm's output $x$ is remunerated at a price equal to the aggregate price level adjusted by the factor $z^{-1}$ as shown in the main text. Since (to a first order approximation) $y=z \cdot x$ the revenue from selling $x$ is equivalent to the value of retail output.
} 


\section{A.1.5 Log-linearised model under rational expectations}

We now log-linearise the model equations around the steady state analysed in Section A.1.4. We denote $\hat{k}_{t} \equiv \ln \left(k_{t} / k\right)$ as the log deviation of $k_{t}$ from its steady state level $k$. Linearising the first order condition for consumption 14 and labour supply 18 (using the linearised first order condition for bond holdings 16) gives

$$
\begin{gathered}
\hat{c}_{t}=E_{t-1} \hat{c}_{t+1}-\sigma^{-1} E_{t-1}\left(\hat{R}_{t}-\hat{\Pi}_{t+1}\right) \\
\hat{h}_{t}=\gamma^{-1} \hat{w}_{t}-\sigma \gamma^{-1} \hat{c}_{t}
\end{gathered}
$$

The linearised resource constraint is

$$
\hat{y}_{t}=\left(1-\psi_{g}\right) \hat{c}_{t}+\psi_{g} \hat{g}_{t}
$$

and the process for government spending satisfies

$$
\hat{g}_{t}=\rho_{g} \hat{g}_{t-1}+u_{t}^{g}
$$

The linearised monetary policy rule is

$$
\hat{R}_{t}=\left(1-\phi_{r}\right)\left(\phi_{\pi} \hat{\Pi}_{t-1}+\phi_{y} \hat{y}_{t-1}\right)+\phi_{r} \hat{R}_{t-1}+u_{t}^{R}
$$

The production function implies that ${ }^{24}$

$$
\hat{y}_{t}-\hat{z}_{t}=\hat{a}_{t}+\hat{h}_{t}
$$

where productivity follows the process

$$
\hat{a}_{t}=\rho_{a} \hat{a}_{t-1}+u_{t}^{a}
$$

The pricing equation implies that

$$
E_{t-1} \sum_{s=t}^{\infty}(\beta \alpha)^{s-t}\left[\left(\hat{p}_{t}^{*}-\hat{\Pi}_{t, s}\right)-\left(\hat{w}_{s}-\hat{a}_{s}\right)\right]=0
$$

or

$$
\begin{aligned}
\hat{p}_{t}^{*} & =(1-\beta \alpha) E_{t-1} \sum_{s=t}^{\infty}(\beta \alpha)^{s-t}\left(\hat{w}_{s}-\hat{a}_{s}+\hat{\Pi}_{t, s}\right) \\
& =(1-\beta \alpha) E_{t-1}\left[\hat{w}_{t}-\hat{a}_{t}+\hat{\Pi}_{t}\right]+(1-\beta \alpha) E_{t-1} \sum_{s=t+1}^{\infty}(\beta \alpha)^{s-t}\left(\hat{w}_{s}-\hat{a}_{s}+\hat{\Pi}_{t, s}\right) \\
& =(1-\beta \alpha) E_{t-1}\left[\hat{w}_{t}-\hat{a}_{t}+\hat{\Pi}_{t}\right]+\beta \alpha(1-\beta \alpha) E_{t-1} \sum_{s=t+1}^{\infty}(\beta \alpha)^{s-(t+1)}\left(\hat{w}_{s}-\hat{a}_{s}+\hat{\Pi}_{t+1, s}+\hat{\Pi}_{t}\right) \\
& =(1-\beta \alpha) E_{t-1}\left[\hat{w}_{t}-\hat{a}_{t}\right]+E_{t-1} \hat{\Pi}_{t}+\beta \alpha E_{t-1} \hat{p}_{t+1}^{*}
\end{aligned}
$$

\footnotetext{
${ }^{24}$ This equation is subject to the caveat noted in footnote $[\mathrm{x}]$ in the main text.
} 
where the final equality makes use of the law of iterated conditional expectations. Linearising the expression for the aggregate price level gives:

$$
\begin{gathered}
1=\alpha\left(\frac{1}{z_{t} \Pi_{t}}\right)^{\frac{\mu-1}{\mu}}+(1-\alpha)\left(\frac{p_{t}^{*}}{z_{t} \Pi_{t}}\right)^{\frac{\mu-1}{\mu}} \\
0=-\alpha\left(\hat{\Pi}_{t}+\hat{z}_{t}\right)+(1-\alpha)\left[\hat{p}_{t}^{*}-\hat{\Pi}_{t}-\hat{z}_{t}\right]
\end{gathered}
$$

so that

$$
\hat{\Pi}_{t}=(1-\alpha) \hat{p}_{t}^{*}-\hat{z}_{t}
$$

Using this information in the log-linearised pricing equation gives:

$$
\hat{\Pi}_{t}=(1-\alpha)(1-\beta \alpha) E_{t-1}\left[\hat{w}_{t}-\hat{a}_{t}\right]+(1-\alpha) E_{t-1} \tilde{\Pi}_{t}+\alpha \beta E_{t-1} \hat{\Pi}_{t+1}-\rho_{z}\left(1-\alpha \beta \rho_{z}\right) z_{t-1}-u_{t}^{z}
$$

which is a version of the New Keynesian Phillips curve. Note that here we have substituted out for the expectations (based on date $t-1$ information) of the $z$ shock. Equations 19-26 can be solved for the eight variables in the model: $\{\hat{c}, \hat{h}, \hat{y}, \hat{R}, \hat{a}, \hat{g}, \hat{\Pi}, \hat{w}\} .^{25}$

\section{A.2 The model under non-rational expectations}

Here we focus on how the decision rules of households and firms are affected by the use of non-rational expectations. We will linearise the model equations around the same steady state analysed in Section A.1.4 and many of the linearised equations will carry across from the rational expectations case presented in Section A.1.5.

\section{A.3 Households}

As noted in the main text, household $i \in(0,1)$ solves:

$$
\max \tilde{E}_{i, t-1} \sum_{s=t}^{\infty} \beta^{s-t}\left[\frac{c_{i, s}^{1-\sigma}}{1-\sigma}-\chi \frac{h_{i, s}^{1+\gamma}}{1+\gamma}\right]
$$

subject to

$$
b_{i, s}-\frac{R_{s-1}}{\Pi_{s}} b_{i, s-1}-w_{s} h_{i, s}-d_{s}+c_{i, s}=0
$$

The Lagrangean for the problem is formed in the same way as in the rational expectations version and gives rise to the following first order conditions for $c_{i}, h_{i}$ and $b_{i}$ :

$$
\tilde{E}_{i, t-1}\left[c_{i, s}^{-\sigma}-\lambda_{i, s}\right]=0
$$

\footnotetext{
${ }^{25}$ Solutions for other variables, such as net dividend payments can be derived recursively.
} 


$$
\begin{gathered}
\tilde{E}_{i, t-1}\left[-\chi h_{i, s}^{\gamma}+\lambda_{i, s} w_{s}\right]=0 \\
\tilde{E}_{i, t-1}\left[-\lambda_{i, s}+\frac{\beta R_{s}}{\Pi_{s+1}} \lambda_{i, s+1}\right]=0
\end{gathered}
$$

for $s=t, t+1, \ldots$ The only difference from the rational expectations case at this stage is that the expectations operator $\tilde{E}_{i, t-1}$ replaces the rational expectations operator $E_{t-1}$.

To proceed, we first log-linearise the equations around the steady state described in Section A.1.4. As before $\hat{x}_{t} \equiv \ln \left(x_{t} / x\right)$ denotes the log deviation of $x_{t}$ from its steady state level $x$. We also define $\tilde{x}_{t} \equiv\left(x_{t}-x\right)$ as the absolute difference of $x_{t}$ from its steady state. The latter will be used for bond holdings, since we linearise around a steady state in which bond market clearing implies $b=0$. Linearising gives:

$$
\begin{gathered}
\left(\begin{array}{c}
\tilde{b}_{i, s}-\beta^{-1} \tilde{b}_{i, s-1}-(1-\mu)\left(\hat{w}_{i, s}^{\prime}+\hat{h}_{s}-\hat{\Pi}_{s}\right) \\
-\left(\mu-\psi_{g}\right) \hat{d}_{s}+\left(1-\psi_{g}\right) \hat{c}_{i, s}
\end{array}\right)=0 \\
\tilde{E}_{i, t-1}\left[-\sigma \hat{c}_{i, s}-\hat{\lambda}_{i, s}\right]=0 \\
\tilde{E}_{i, t-1}\left[\gamma \hat{h}_{i, s}-\hat{w}_{s}-\hat{\lambda}_{i, s}\right]=0 \\
\tilde{E}_{i, t-1}\left[-\hat{\lambda}_{i, s}+\hat{\lambda}_{i, s+1}+\left(\hat{R}_{s}-\hat{\Pi}_{s+1}\right)\right]=0
\end{gathered}
$$

where we make use of the fact that in the steady state: $\beta R / \Pi=1 ; w=1-\mu ; h=1$; $d=\mu-\psi_{g}$ and $c=1-\psi_{g}{ }^{26}$

To derive the decision rules, we begin with the budget constraint 27 . We know that:

$$
\begin{gathered}
\tilde{E}_{i, t-1}\left[\begin{array}{c}
\tilde{b}_{i, t}-\beta^{-1} \tilde{b}_{i, t-1}-(1-\mu)\left(\hat{w}_{t}+\hat{h}_{i, t}\right) \\
-\left(\mu-\psi_{g}\right) \hat{d}_{t}+\left(1-\psi_{g}\right) \hat{c}_{i, t}
\end{array}\right]=0 \\
\tilde{E}_{i, t-1}\left[\begin{array}{c}
\tilde{b}_{i, t+1}-\beta^{-1} \tilde{b}_{i, t}-(1-\mu)\left(\hat{w}_{t+1}+\hat{h}_{i, t+1}\right) \\
-\left(\mu-\psi_{g}\right) \hat{d}_{t+1}+\left(1-\psi_{g}\right) \hat{c}_{i, t+1}
\end{array}\right]=0
\end{gathered}
$$

which means that we can combine the equations to give:

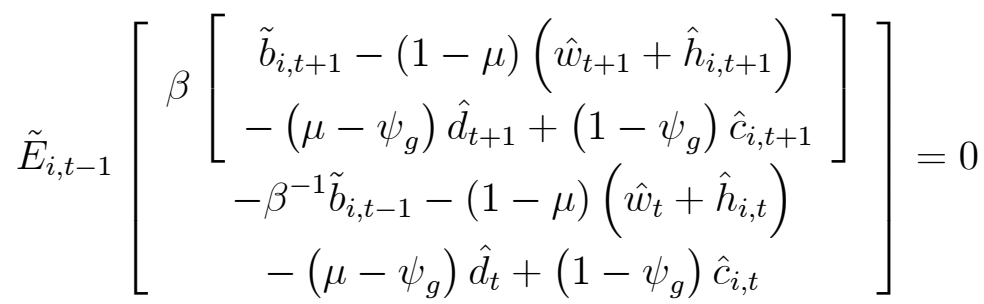

\footnotetext{
${ }^{26}$ Note also that equation 27 contains a term representing the interest component of income from bond holdings (given by $-b \beta^{-1}\left(\hat{R}_{s-1}-\hat{\Pi}_{s}\right)$ ) which disappears when we linearise around the steady state described in Section A.1.4, in which $b=0$.
} 
Repeated substitution in this fashion yields:

$$
\tilde{E}_{i, t-1}\left[\lim _{s \rightarrow \infty} \beta^{s-t} \tilde{b}_{i, s+1}+\sum_{s=t}^{\infty} \beta^{s-t}\left(\begin{array}{c}
\left(1-\psi_{g}\right) \hat{c}_{i, s}-\beta^{-1} \tilde{b}_{i, t-1}-\left(\mu-\psi_{g}\right) \hat{d}_{s} \\
-(1-\mu)\left(\hat{w}_{s}+\hat{h}_{i, s}\right)
\end{array}\right)\right]=0
$$

or

$$
\begin{aligned}
& \tilde{E}_{i, t-1} \sum_{s=t}^{\infty} \beta^{s-t}\left(1-\psi_{g}\right) \hat{c}_{i, s} \\
= & \tilde{E}_{i, t-1} \sum_{s=t}^{\infty} \beta^{s-t}\left(\begin{array}{c}
\beta^{-1} \tilde{b}_{i, t-1}+\left(\mu-\psi_{g}\right) \hat{d}_{s} \\
+(1-\mu)\left(\hat{w}_{s}+\hat{h}_{i, s}\right)
\end{array}\right)
\end{aligned}
$$

where we have imposed the constraint:

$$
\lim _{s \rightarrow \infty} \tilde{E}_{i, t-1} \beta^{s-t} \tilde{b}_{i, s+1}=0
$$

which is standard in the RE literature. In this context the assumption represents the assumption that the household's perceptions about wealth are in some sense bounded. Households are not allowed to believe that they can increase their borrowing faster than the financing requirements in the long run. Imposing this assumption means that we will be able to derive a consumption function from the conventional condition stating that the households's expected consumption stream exhausts the present value of their expected net income.

How strong is this assumption? Under rational expectations, conditions of this type will generally hold (at least along the equilibrium path if not under more general conditions). But there is no reason to assume that the behaviour of a household with arbitrary expectations over future events will satisfy this constraint. This means that our model effectively focuses attention on expectations schemes that have 'sensible' long-run properties. Moreover, in principle we should check on a case-by-case basis whether the expectations implied by the forecasting rules that we consider satisfy this constraint. We expect that general 'VAR' expectations of the form considered in Section 2.2.4 will satisfy this constraint as long as the eigenvalues in the projection matrices are not too large. It is not clear, however, that ruling out 'bubble' solutions in consumption decisions offers the best chance of generating strong expectational dynamics: laboratory experiments with subjects based on asset pricing models suggest that trend following behaviour can coordinate expectations on paths that look (locally) like explosive bubble solutions as shown by Anufriev \& Hommes (2006).

To proceed, we combine 28 and 29 to give:

$$
\tilde{E}_{i, t-1} h_{i, s}=\tilde{E}_{i, t-1}\left[\gamma^{-1} \hat{w}_{s}-\frac{\sigma}{\gamma} \hat{c}_{i, s}\right]
$$


Using this information allows us to write 31 as:

$$
\begin{aligned}
& \tilde{E}_{i, t-1} \sum_{s=t}^{\infty} \beta^{s-t}\left[1-\psi_{g}+\frac{\sigma(1-\mu)}{\gamma}\right] \hat{c}_{i, s} \\
= & \tilde{E}_{i, t-1} \sum_{s=t}^{\infty} \beta^{s-t}\left(\begin{array}{c}
\beta^{-1} \tilde{b}_{i, t-1}+\left(\mu-\psi_{g}\right) \hat{d}_{s} \\
+(1-\mu)\left(1+\gamma^{-1}\right) \hat{w}_{s}
\end{array}\right)
\end{aligned}
$$

Combining 28 and 30 allows us to see that:

$$
\tilde{E}_{i, t-1} \hat{c}_{i, t+1}=\tilde{E}_{i, t-1}\left[\hat{c}_{i, t}+\frac{1}{\sigma}\left(\hat{R}_{t}-\hat{\Pi}_{t+1}\right)\right]
$$

and that in general

$$
\begin{aligned}
\tilde{E}_{i, t-1} \hat{c}_{i, s} & =\tilde{E}_{i, t-1}\left[\hat{c}_{i, t}+\frac{1}{\sigma} \sum_{k=t+1}^{s}\left(\hat{R}_{k-1}-\hat{\Pi}_{k}\right)\right] \\
& =\tilde{E}_{i, t-1}\left[\hat{c}_{i, t}+\frac{1}{\sigma} S_{t, s}^{R}\right]
\end{aligned}
$$

for $s=t+1, t+2, \ldots$ where

$$
S_{t, s}^{R} \equiv\left\{\begin{array}{cc}
0 & s=t \\
\sum_{i=t+1}^{s}\left(\hat{R}_{s-1}-\hat{\Pi}_{s}\right) & s=t+1, t+2, \ldots
\end{array}\right.
$$

Putting this into 32 gives:

$$
\begin{aligned}
& {\left[1-\psi_{g}+\frac{\sigma(1-\mu)}{\gamma}\right] \tilde{E}_{i, t-1} \sum_{s=t}^{\infty} \beta^{s-t}\left[\hat{c}_{i, t}+\frac{1}{\sigma} S_{t, s}^{R}\right] } \\
= & \tilde{E}_{i, t-1} \sum_{s=t}^{\infty} \beta^{s-t}\left(\begin{array}{c}
(1-\mu)\left(1+\gamma^{-1}\right) \hat{w}_{s} \\
+\beta^{-1} \tilde{b}_{i, t-1}+\left(\mu-\psi_{g}\right) \hat{d}_{s}
\end{array}\right)
\end{aligned}
$$

which can be written as:

$$
\begin{aligned}
& \hat{c}_{i, t}=\frac{1-\beta}{1-\psi_{g}+\frac{\sigma(1-\mu)}{\gamma}} \tilde{E}_{i, t-1} \sum_{s=t}^{\infty} \beta^{s-t}\left(\begin{array}{c}
(1-\mu)\left(1+\gamma^{-1}\right) \hat{w}_{s} \\
+\beta^{-1} \tilde{b}_{i, t-1}+\left(\mu-\psi_{g}\right) \hat{d}_{s}
\end{array}\right) \\
& -\frac{1-\beta}{\sigma} \tilde{E}_{i, t-1} \sum_{s=t+1}^{\infty} \beta^{s-t} S_{t, s}^{R}
\end{aligned}
$$

To complete the description of the consumption equation, we need to unpack the final 
term:

$$
\begin{aligned}
\tilde{E}_{i, t-1} \sum_{s=t+1}^{\infty} \beta^{s-t} S_{t, s}^{R} & =\tilde{E}_{i, t-1} \sum_{s=t+1}^{\infty} \beta^{s-t} \sum_{k=t+1}^{s}\left(\hat{R}_{k-1}-\hat{\Pi}_{k}\right) \\
& =\tilde{E}_{i, t-1}\left[\begin{array}{l}
\beta\left(\hat{R}_{t}-\hat{\Pi}_{t+1}\right)+ \\
\beta^{2}\left(\hat{R}_{t}-\hat{\Pi}_{t+1}\right)+\beta^{2}\left(\hat{R}_{t+1}-\hat{\Pi}_{t+2}\right)+ \\
\beta^{3}\left(\hat{R}_{t}-\hat{\Pi}_{t+1}\right)+\beta^{3}\left(\hat{R}_{t+1}-\hat{\Pi}_{t+2}\right)+\beta^{3}\left(\hat{R}_{t+2}-\hat{\Pi}_{t+3}\right)+ \\
\cdots
\end{array}\right] \\
= & \tilde{E}_{i, t-1} \sum_{s=t+1}^{\infty} \frac{\beta^{s-t}}{1-\beta}\left(\hat{R}_{s-1}-\hat{\Pi}_{s}\right)
\end{aligned}
$$

so that the consumption equation can be written:

$$
\begin{aligned}
\hat{c}_{i, t}= & \frac{1-\beta}{1-\psi_{g}+\frac{\sigma(1-\mu)}{\gamma}} \tilde{E}_{i, t-1} \sum_{s=t}^{\infty} \beta^{s-t}\left(\begin{array}{c}
(1-\mu)\left(1+\gamma^{-1}\right) \hat{w}_{s} \\
+\beta^{-1} \tilde{b}_{i, t-1}+\left(\mu-\psi_{g}\right) \hat{d}_{s}
\end{array}\right) \\
& -\frac{\beta}{\sigma} \tilde{E}_{i, t-1} \sum_{s=t}^{\infty} \beta^{s-t}\left(\hat{R}_{s}-\hat{\Pi}_{s+1}\right)
\end{aligned}
$$

\section{A.4 Firms}

The environment faced by firms is essentially the same as that described in Section 2.1.2. To analyse their optimal pricing decision, we begin with a version of the pricing equation 17 derived in Section 2.1.2:

$$
\bar{E}_{j, t-1} \sum_{s=t}^{\infty} \Lambda_{s}(\beta \alpha)^{s-t}\left(\frac{\mu-1}{\mu} \frac{p_{j, t}}{\Pi_{t, s}}+\frac{1}{\mu} \frac{w_{s}}{a_{s}}\right)\left(\frac{p_{j, t}}{\Pi_{t, s}}\right)^{-\frac{1}{\mu}} z_{s}^{\frac{1-\mu}{\mu}} y_{s}=0
$$

where in this case the only difference from equation 17 is that the expectation of firm $j$ is denoted as the (non-rational) expectation $\bar{E}_{j, t-1}$.

Linearising around the steady state described in Section A.1.4 gives:

$$
\bar{E}_{j, t-1} \sum_{s=t}^{\infty}(\beta \alpha)^{s-t}\left[\left(\hat{p}_{j, t}-\hat{\Pi}_{t, s}\right)-\left(\hat{w}_{s}-\hat{a}_{s}\right)\right]=0
$$

or

$$
\hat{p}_{j, t}=(1-\beta \alpha) \bar{E}_{j, t-1} \sum_{s=t}^{\infty}(\beta \alpha)^{s-t}\left(\hat{w}_{s}-\hat{a}_{s}+\hat{\Pi}_{t, s}\right)
$$


To complete the derivation of the optimal relative price, consider the final term:

$$
\begin{aligned}
\bar{E}_{j, t-1} \sum_{s=t}^{\infty}(\beta \alpha)^{s-t} \hat{\Pi}_{t, s}=\bar{E}_{j, t-1}\left[\begin{array}{l}
\hat{\Pi}_{t}+ \\
\beta \alpha \hat{\Pi}_{t}+\beta \alpha \hat{\Pi}_{t+1}+ \\
(\beta \alpha)^{2} \hat{\Pi}_{t}+(\beta \alpha)^{2} \hat{\Pi}_{t+1}+(\beta \alpha)^{2} \hat{\Pi}_{t+2}+ \\
\ldots
\end{array}\right] \\
=\bar{E}_{j, t-1}\left[\begin{array}{l}
\hat{\Pi}_{t}\left(1+\beta \alpha+(\beta \alpha)^{2}+\ldots\right)+ \\
\hat{\Pi}_{t+1}\left(\beta \alpha+(\beta \alpha)^{2}+(\beta \alpha)^{3}+\ldots\right)+ \\
\hat{\Pi}_{t+2}\left((\beta \alpha)^{2}+(\beta \alpha)^{3}+(\beta \alpha)^{4}+\ldots\right)+\ldots
\end{array}\right] \\
=\bar{E}_{j, t-1} \sum_{s=t}^{\infty} \frac{(\beta \alpha)^{s-t}}{1-\beta \alpha} \hat{\Pi}_{s}
\end{aligned}
$$

so that the optimal relative price can be written as:

$$
\hat{p}_{j, t}=(1-\beta \alpha) \bar{E}_{j, t-1} \sum_{s=t}^{\infty}(\beta \alpha)^{s-t}\left(\hat{w}_{s}-\hat{a}_{s}\right)+\bar{E}_{j, t-1} \sum_{s=t}^{\infty}(\beta \alpha)^{s-t} \hat{\Pi}_{s}
$$

\section{A.5 Aggregation}

As explained in the text, we assume that there are a finite set of 'predictors' available to each group of agents. From this point on we will use the index $i(j)$ to denote the decisions of a household (firm) using predictor $i \in\{1, \ldots, I\}(j \in\{1, \ldots, J\})$. The mass of households (firms) using predictor $i(j)$ is given by $n_{i}\left(m_{j}\right)$ where

$$
\sum_{i=1}^{I} n_{i}=\sum_{j=1}^{J} m_{j}=1
$$

This means that the model equations can be written as follows. The average re-set price of firms is

$$
\begin{aligned}
& \hat{p}_{t}^{*}=\sum_{j=1}^{J} m_{j, t} \hat{p}_{j, t} \\
& =(1-\beta \alpha) \sum_{j=1}^{J} m_{j, t} \bar{E}_{j, t-1} \sum_{s=t}^{\infty}(\beta \alpha)^{s-t}\left(\hat{w}_{s}-\hat{a}_{s}\right)+\sum_{j=1}^{J} m_{j, t} \bar{E}_{j, t-1} \sum_{s=t}^{\infty}(\beta \alpha)^{s-t} \hat{\Pi}_{s}
\end{aligned}
$$

where, for each $j \in\{1, \ldots, J\}, m_{j}$ is the fraction of firms setting price $\hat{p}_{j}$.

Inflation is given by:

$$
\hat{\Pi}_{t}=(1-\alpha) \hat{p}_{t}^{*}-\hat{z}_{t}
$$

The linearised resource constraint and monetary policy rule are the same as in the rational expectations model:

$$
\begin{gathered}
\hat{y}_{t}=\left(1-\psi_{g}\right) \hat{c}_{t}+\psi_{g} \hat{g}_{t} \\
\hat{R}_{t}=\left(1-\phi_{r}\right)\left(\phi_{\pi} \hat{\Pi}_{t-1}+\phi_{y} \hat{y}_{t-1}\right)+\phi_{r} \hat{R}_{t-1}+u_{t}^{R}
\end{gathered}
$$


The average level of consumption is:

$$
\begin{aligned}
\hat{c}_{t} & =\sum_{i=1}^{I} n_{i, t} \hat{c}_{i, t} \\
& =\frac{1-\beta}{1-\psi_{g}+\frac{\sigma(1-\mu)}{\gamma}} \sum_{i=1}^{I} n_{i, t} \tilde{E}_{i, t-1} \sum_{s=t}^{\infty} \beta^{s-t}\left[(1-\mu)\left(1+\gamma^{-1}\right) \hat{w}_{s}+\left(\mu-\psi_{g}\right) \hat{d}_{s}\right] \\
& -\frac{\beta}{\sigma} \sum_{i=1}^{I} n_{i, t} \tilde{E}_{i, t-1} \sum_{s=t+1}^{\infty} \beta^{s-t}\left(\hat{R}_{s}-\hat{\Pi}_{s+1}\right)
\end{aligned}
$$

where we use the fact that bond market clearing requires:

$$
\sum_{i=1}^{I} n_{i, s} \tilde{b}_{i, s}=0
$$

for all $s$.

Turning to the labour market, we note that our assumptions about the worker/shopper behaviour of the household gives:

$$
\hat{w}_{t}=\gamma \hat{h}_{t}+\sigma \hat{c}_{t}
$$

where we exploit the log-linear form of the labour supply choice of the household's 'worker'.

Noting that $\hat{h}_{t}=\hat{y}_{t}-\hat{a}_{t}-\hat{z}_{t}=\left(1-\psi_{g}\right) \hat{c}_{t}+\psi_{g} \hat{g}_{t}-\hat{a}_{t}-\hat{z}_{t}$ we have:

$$
\hat{w}_{t}=\left[\gamma\left(1-\psi_{g}\right)+\sigma\right] \hat{c}_{t}+\gamma \psi_{g} \hat{g}_{t}-\gamma \hat{a}_{t}-\gamma \hat{z}_{t}
$$

In this version of the model we need to solve out for net dividends since households must forecast this variable when making their consumption plans. We can see that the definition of dividends and the market clearing conditions imply:

$$
d_{t}=\Delta_{t}-\tau_{t}
$$

in equilibrium this is given by:

$$
d_{t}=y_{t}-w_{t} h_{t}-g_{t}
$$

which means that

$$
\hat{d}_{t}=\frac{\left(1-\psi_{g}\right) \mu}{\mu-\psi_{g}} \hat{c}_{t}-\frac{1-\mu}{\mu-\psi_{g}} \hat{w}_{t}-\frac{(1-\mu) \psi_{g}}{\mu-\psi_{g}} \hat{g}_{t}+\frac{1-\mu}{\mu-\psi_{g}} \hat{a}_{t}+\frac{1-\mu}{\mu-\psi_{g}} \hat{z}_{t}
$$

\section{B Calibration of the intensities of choice}

The procedure for setting the elements of $\theta$ is a simple iterative one. We start with an initial guess for $\theta$ and solve for the predictor proportions $\left(m^{* *}, n^{* *}\right)$ that represent the fixed point of the following mappings:

$$
\begin{aligned}
m^{*} & =T_{f}\left(m^{*}, n\right) \\
n^{*} & =T_{h}\left(m, n^{*}\right)
\end{aligned}
$$


which solve for the optimal asymptotic values of $m$ and $n$ as a function of the pair $(m, n) \cdot{ }^{27}$ To derive the mapping $T_{f}$ we perform the following experiment. For each value of $n$ we find the $m^{*}$ which would be generated asymptotically by the predictor choice mapping (that is if the predictor proportions remained at $n$ and $m^{*}$ ) forever. The $T_{h}$ mapping is constructed analogously and the point $\left(m^{* *}, n^{* *}\right)$ represents the intersection of these curves in $(m, n)$ space. $^{28}$ With this information in hand we examine whether

$$
\left[\begin{array}{c}
n^{* *} \Xi_{1}^{h}\left(m^{* *}, n^{* *}\right)+\left(1-n^{* *}\right) \Xi_{2}^{h}\left(m^{* *}, n^{* *}\right) \\
m^{* *} \Xi_{1}^{f}\left(m^{* *}, n^{* *}\right)+\left(1-m^{* *}\right) \Xi_{2}^{f}\left(m^{* *}, n^{* *}\right)
\end{array}\right]-\iota<\varepsilon \cdot \iota
$$

where $\varepsilon>0$ is a small number and the mean squared errors are evaluated (as the notation suggests) using the asymptotic representation of the model with predictor proportions $\left(m^{* *}, n^{* *}\right)$. If this condition is satisfied we stop the process and accept the vector $\theta$. If it is not satisfied we try another guess for $\theta$. The sequence of guesses are guided by a numerical optimisation procedure.

This approach, though arbitrary, ensures that predictor choice is not dominated by the behaviour of a subset of very volatile variables. There are other ways that we could calibrate the intensities of choice which we intend to examine in further work. One approach might be to replace the $\iota$ vector with a vector of weights representing the relative importance of each variable to household's utility or firm's profits. Another would be to use evidence from predictor choice models that have been fitted to behaviour observed in laboratory experiments as in Anufriev \& Hommes (2006).

\footnotetext{
${ }^{27}$ These mappings are similar to the 'T-maps' considered in the predictor choice literature - see for example Branch (2004).

${ }^{28}$ Our approach assumes that this point is unique, though it need not be. For our applications, however, there is indeed a unique point.
} 